\title{
DoE/PC/89804-4
}

DE-AC22-89PC89804-04

\section{INTEGRATED EMISSIONS CONTROL SYSTEM FOR RESIDENTIAL CWS FURNACE}

\section{Annual Status Report Number 1}

Report Period: September 20, 1989 to September 30, 1990

By

J.C. Balsavich and R.W. Breault

\section{DISCLAIMER}

This report was prepared as an account of work sponsored by an agency of the United States Government. Neither the United States Government nor any agency thereof, nor any of their employees, makes any warranty, express or implied, or assumes any legal liability or responsibility for the accuracy, completeness, or usefulness of any information, apparatus, product, or process disclosed, or represents that its use would not infringe privately owned rights. Reference herein to any specific commercial product, process, or service by trade name, trademark, manufacturer, or otherwise does not necessarily constitute or imply its endorsement, recommendation, or favoring by the United States Government or any agency thereof. The views and opinions of authors expressed herein do not necessarily state or reflect those of the United States Government or any agency thereof.

Work Performed Under Contract No. DE-AC22-89PC89804

September 20, 1989 to March 20, 1992

Tecogen Inc.

45 First Avenue

P.O. Box 9046

Waltham, Massachusetts $\quad 02254-9046$ 


\section{DISCLAIMER}

"This report was prepared as an account of work sponsored by an agency of the United States Government. Neither the United States Government nor any agency thereof, nor any of their employees, makes any warranty, express or implied, or assumes any legal liability or responsibility for the accuracy, completeness, or usefulness of any information, apparatus, product, or process disclosed, or represents that its use would not infringe privately owned rights. Reference herein to any specific commercial product, process, or service by trade name, trademark, manufacturer, or otherwise, does not necessarily constitute or imply its endorsement, recommendation, or favoring by the United States Government or any agency thereof. The views and opinions of authors expressed herein do not necessarily state or reflect those of the United States Government or any agency thereof."

This report has been reproduced directly from the best available copy.

Available from the National Technical Information Service, U. S. Department of Commerce, Springfield, Virginia 22161.

Price: Printed Copy A04

Microfiche AOI 


\section{DISCLAIMER}

Portions of this document may be illegible in electronic image products. Images are produced from the best available original document. 


\section{INTEGRATED EMUSSIONS CONTROL SYSTEM FOR RESIDENTIAL CWS FURNACE}

Annual Status Report Number 1

Report Period: September 20, 1989 to September 30, 1990

October 1990

Work Performed Under Contract DE-AC22-89PC89804

September 20, 1989 to March 20, 1992

Prepared for PETC Project Manager: Thomas D. Brown

Pittsburgh Energy Technology Center U.S. Department of Energy

P.O. Box 10940

Pittsburgh, Pennsylvanla 15236-0940

Prepared by

J.C. Balsavich and R.W. Breault

Tecogen Inc.

45 First Avenue

P.O. Box 9046

Waltham, Massachusetts 02254-9046 


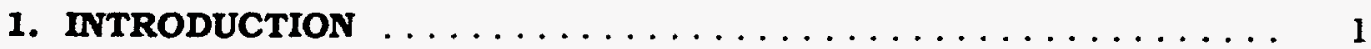

2. PROGRAM OBJECTIVE $\ldots \ldots \ldots \ldots \ldots \ldots \ldots \ldots \ldots \ldots$

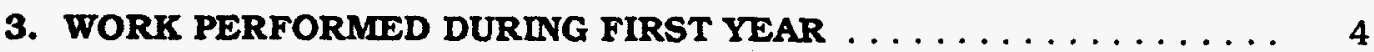

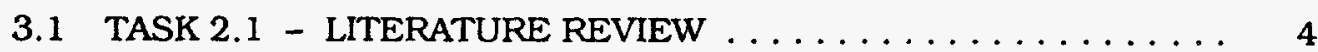

3.1 .1 Coal Combustion $\ldots \ldots \ldots \ldots \ldots \ldots \ldots \ldots \ldots \ldots$

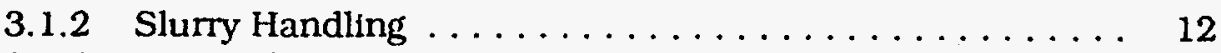

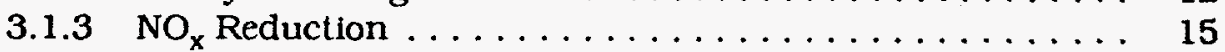

3.1.4 Sulfur Dioxide Removal $\ldots \ldots \ldots \ldots \ldots \ldots \ldots \ldots$

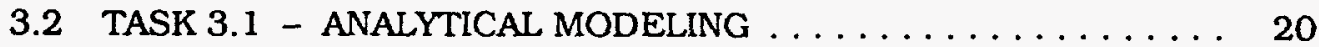

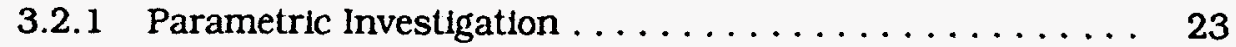

3.3 TASK 3.2 - PROTOTYPE COMPONENT DESIGN . . . . . . . . 31

3.3.1 $\mathrm{NO}_{\mathrm{x}}$ Reduction Test Facillity $\ldots \ldots \ldots \ldots \ldots \ldots \ldots \ldots \ldots \ldots$

3.3.2 $\mathrm{SO}_{2}$ Reduction Test Facllity $\ldots \ldots \ldots \ldots \ldots \ldots \ldots \ldots$

3.4 TASK 4.1 - INITIAL PROTOTYPE COMPONENT FABRICATION AND ASSEMBLY $\ldots \ldots \ldots \ldots \ldots \ldots \ldots \ldots \ldots \ldots \ldots$

3.5 TASK 5 - INITIAL PROTOTYPE COMPONENT TESTING . . . . . 40

3.5.1 $\mathrm{NO}_{\mathrm{x}}$ Reduction Testing $\ldots \ldots \ldots \ldots \ldots \ldots \ldots \ldots \ldots$

3.5.2 $\mathrm{SO}_{2}$ Reduction Testing $\ldots \ldots \ldots \ldots \ldots \ldots \ldots \ldots \ldots \ldots$

3.5.3 Particulate Control .................. 58

3.6 TASK 7.1 - PRELIMINARY MANUFACTURING COST ESTIMATE . 62

4. SUMMARY STATUS ASSESSMENT AND FORECAST $\ldots \ldots \ldots \ldots 6$

REFERENCES $\quad \ldots \ldots \ldots \ldots \ldots \ldots \ldots \ldots \ldots \ldots \ldots \ldots \ldots \ldots$ 


\section{LIST OI ILLUSTRATIONS}

3.1 Peristaltic Pump with Dual Pump Heads . . . . . . . . . . . . 14

$3.2 \quad$ Nitrogen Pathway $\ldots \ldots \ldots \ldots \ldots \ldots \ldots \ldots \ldots \ldots$

3.3 Effect of Particle Diameter on Reactor Performance ......... 26

3.4 Effect of $\mathrm{SO}_{2}$ Concentration on Reactor Performance ........ 27

3.5 Effect of Calcium-to-Sulfur Ratio on Reactor Performance . . . . . . 29

3.6 Effect of Reactor Height on Reactor Performance . . . . . . . . . 30

3.7 Effect of Input Rate on Reactor Performance . . . . . . . . . 32

3.8 Effect of Input Rate on Optimal Particle Diameter . . . . . . . . 33

$3.9 \quad \mathrm{NO}_{\mathbf{x}}$ Reduction Test Facility $\ldots \ldots \ldots \ldots \ldots \ldots \ldots \ldots \ldots$

3.10 Cutaway Drawing of CWS-Fired Residential Combustor ...... 36

3.11 Atomizer Operating with oll $\ldots \ldots \ldots \ldots \ldots \ldots \ldots \ldots$

$3.12 \mathrm{SO}_{2}$ Removal Test Facility $\ldots \ldots \ldots \ldots \ldots \ldots \ldots \ldots$

3.13 Normalized Static Pressure Distributions Inside Axial Recirculation Emissions Control Reactor .......... 39

3.14 External and Internal Circulation in the Emissions Control Reactor . . . . . . . . . . . 41

3.15 Emissions Control Reactor Model (High Load) Intensive External and Internal Circulation . . . . . . . 42

3.16 Pholograph of $\mathrm{NO}_{x}$ Test Facility .............. 43

$3.17 \mathrm{SO}_{2}$ Test Facility $\ldots \ldots \ldots \ldots \ldots \ldots \ldots \ldots \ldots \ldots \ldots$

$3.18 \mathrm{NO}_{x}$ as a Function of Stoichiometric Ratio for Unstaged Operation . . . . . . . . . . . . . 47

3.19 Weight Percent of Total $\mathrm{NO}_{\mathrm{x}}$ in the Form of $\mathrm{NO}_{2}$ as a Function of Stolchiometric Ratio ..............

3.20 Thermochemical Equilibrium $\mathrm{NO}_{x}$ Concentration as a Function of Temperature and Stoichiometric Ratio for the Combustion of Coal Water Slurry . . . . . . . . . .

3.21 Combustor Configurations $\ldots \ldots \ldots \ldots \ldots \ldots \ldots$ 


\section{LIST OF ILLUSTRATIONS (Continued)}

3.22 Comparison Between Combustor Configurations $\ldots \ldots \ldots \ldots \ldots 2$

3.23 Comparison Between Combustor Configurations $\ldots \ldots \ldots \ldots \ldots$

3.24 Effect of Primary/Stoichlometric Ratio on $\mathrm{NO}_{2}$ Emissions for Staged Combustion ................. 55

3.25 Particle Size Distribution for Limestone $1 \ldots \ldots \ldots$

3.26 Particle Size Distribution for Limestone $1 \ldots \ldots \ldots \ldots$

3.27 $\mathrm{SO}_{2}$ Concentration as a Function of Time for Various $\mathrm{Ca} / \mathrm{S}$ Ratios . . . . . . . . . . . . . . . 59

3.28 Effect of $\mathrm{Ca} / \mathrm{S}$ Ratio on Reactor Performance $\ldots \ldots \ldots \ldots$

3.29 Venturis and Cages $\ldots \ldots \ldots \ldots \ldots \ldots \ldots \ldots \ldots \ldots \ldots$ 


\section{LIST OF TABLES}

3.1 Carbon-Oxygen Reaction Rate Constants, $\mathbf{k}_{\mathrm{p}} \ldots \ldots \ldots \ldots \ldots$

3.2 Chemical Reactions Involving Fucl $\mathrm{NO}_{x}$ Formation and Destruction $\ldots \ldots \ldots \ldots \ldots \ldots \ldots \ldots \ldots \ldots \ldots \ldots \ldots$

$3.3 \mathrm{SO}_{2}$ Model Parameters $\ldots \ldots \ldots \ldots \ldots \ldots \ldots \ldots \ldots \ldots \ldots$

$3.4 \quad$ Fuel Properties $\ldots \ldots \ldots \ldots \ldots \ldots \ldots \ldots \ldots \ldots \ldots \ldots \ldots$

$3.5 \quad$ Manufacturing Cost Estumate $\ldots \ldots \ldots \ldots \ldots \ldots \ldots$ 


\section{INTRODUCTION}

One of the major obstacles to the successful development and commercialization of a coal-fired residential furnace is the need for a reliable, costeffective emission control system. Ash, sulfur, and fuel-bound nitrogen make the control of $\mathrm{NO}_{\mathbf{x}}, \mathrm{SO}_{\mathbf{x}}$, and particulates much more difficult with coal-based fuels than with either natural gas or oil. While techniques for controlling these emissions in large utility power plants are well advanced, they generally would be too complex and costly to be applied directly to residential applications.

To meet the emission goals set by the Pittsburgh Energy Technology Center (PETC), Tecogen Inc. is developing a novel, integrated emission control system to control $\mathrm{NO}_{\mathbf{x}}, \mathrm{SO}_{2}$, and particulate emissions. At the heart of this system is a unique emissions control reactor for the control of $\mathrm{SO}_{2}$. This reactor provides high sorbent particle residence time within the reactor while doing so in a very compact geometry. In addition to controlling $\mathrm{SO}_{2}$ emissions, the reactor provides a means of extracting a substantial amount of the particulates present in the combustion gases. Final cleanup of any fine particulates exiting the reactor, including respirable-sized particulates, is completed with the use of high efficiency bag filters.

With $\mathrm{SO}_{2}$ and particulate emissions being dealt with by an emissions control reactor and bag filters, the control of $\mathrm{NO}_{x}$ emissions needs to be addressed. Under a previous contract with PETC (contract No. DE-AC22-87PC79650), Tecogen developed a residential-scale Coal Water Slurry (CWS) combustor. This combustor makes use of centrifugal forces, set up by a predominantly tangential flow field, to separate and confine larger unburned coal particles in the furnace upper chamber. Various partitions are used to retard the axial. downward flow of these particles, and thus maximize their residence time in the hottest section of the combustor. By operating this combustor under staged conditions, the local stoichiometry in the primary zone can be controlled in such a manner as to minimize $\mathrm{NO}_{x}$ emissions.

The development program for this project is divided into three facets, each having specific objectives with clear goals that would be met prior to proceeding to the next step. First, all system and component analyses would be completed, and the initial prototype component hardware would be tested and evaluated. Preliminary manufacturing and operating cost estimates would also be made. Second, final prototype hardware would be built and tested, and cost estimates updated. Finally, the entire furnace system would be tested to demonstrate that the emissions goals were met, and the high-volume production cost estimates would be finalized. 
The entire program covers a period of 30 months. The first step will require 12 months, and the next two, 9 months each. This report summarizes work conducted during the first year of the program. 


\section{PROGRAM OBJECTIVE}

The objective of this program is to develop a combined particulate, $\mathrm{SO}_{2}$, and $\mathrm{NO}_{\mathrm{x}}$ integrated control system for flue gas cleanup of residential furnaces fueled by coal water fuel mixtures. Specific objectives for this program are:

- To reduce flue gas emissions from the furnace to the following levels:

$$
\begin{array}{ll}
\mathrm{SO}_{2}: & 0.4 \mathrm{lb} / \mathrm{MMBtu} \\
\mathrm{NO}_{\mathrm{x}}: & 0.2 \mathrm{lb} / \mathrm{MMBtu}
\end{array}
$$

Particulates: $\quad 0.02 \mathrm{lb} / \mathrm{MMBtu}$

(99.9\% capture of particles 0.5 to 10 microns)

- To achieve a high reliability and a service life of 20 years or more by utilizing a simple design concept with no critical moving parts.

- To keep scheduled maintenance to twice a year.

- To achieve efficient sorbent utilization in reducing $\mathrm{SO}_{2}$ so that the volume of ash and spent sorbent collected before removal is acceptable.

- To use a simple design approach to keep manufacturing costs as low as possible.

In order to achieve these objectives, this program has been divided up into 8 individual tasks. These tasks, along with their various subtasks, provide the framework for this project and establish the various goals and milestones. The 8 main tasks for this program are:

Task 1: Project Work Plan

Task 2: System Definition

Task 3: Prototype Component Analysis and Design

Task 4: Prototype Component Fabrication and Assembly

Task 5: Testing and Development

Task 6: Integrated System Operation

Task 7: Economic Evaluation

Task 8: Reporting and Management 


\section{WORK PERFORMED DURING FIRST YEAR}

During the first year of the program, work was conducted on Tasks 1 through 5 and Task 7 . This work encompassed a wide range of the program's scope and included a literature search, developing an analytical model of the $\mathrm{SO}_{2}$ reactor. fabricating, assembling the initial prototype components, testing the prototype component, and estimating the operating and manufacturing costs. A discussion of these activities follows.

\subsection{TASK 2.1 - LITERATURE REVIEW}

A literature review has been conducted to determine the level of understanding of the factors allecting emissions from small-scale coal-fired combustion systems and to form a basis for the development of an analytic model. Literature on coal combustion. slurry handling, $\mathrm{NO}_{\mathrm{x}}$ reduction, and sulfur dioxide removal is summarized below.

\subsubsection{Coal Combustion}

A review of the existing literature on the various aspects of coal and coalwater mixture combustion has been conducted and is provided below. The main topics reviewed are coal make-up, devolatilization, char oxidation, volatile oxidation, soot oxidation, and coal-water mixture oxidation.

Coal is a complex, solid, heterogeneous material of carbon base, capable of supplying energy for heat and processing. The chemical and physical make-up of coal has been studied extensively and continues to be studied. Coal studies are usually divided into two areas - coal chemistry (chemical and physical make-up) and coal utilization (combustion, gasification, and liquefaction).

\section{Coal Chemistry}

Coal is classified by rank and grade. ${ }^{1}$ Coal rank is a method of expressing the progressive metamorphism of coal from lignite (low) to metaanthracite (high). There are four ranks of coal: (1) lignite. (2) subbituminous, (3) bituminous, and (4) anthracite. Each rank has also been subdivided, based on ash-free heating values for low rank coals and moisture-ash-free fixed carbon content for high rank coals. The results of the subdivisions - lowest to highest rank - are: lignite $B$. lignite $A$, subbituminous $C$, subbituminous $B$, subbituminous $A$, high volatile bituminous $C$, high volatile bituminous $B$, high volatile bituminous $A$, medium volatile bituminous, low volatile bituminous, semianthracite, anthracite, and metaanthracite. The heating value increases from $13,900 \mathrm{~kJ} / \mathrm{kg}$ for lignite $B$ to $34,900 \mathrm{~kJ} / \mathrm{kg}$ for low volatile bituminous $\mathrm{A}$ and then decreases to $30,100 \mathrm{~kJ} / \mathrm{kg}$ for 
metaanthracite. The fixed carbon content increases from 25 percent for lignite $B$ to 90 percent for metaanthracite.

Coal is also classified by grade. The three factors that cause coal to have a low grade are: high ash content, low ash fusion temperature, and high sulfur content. Sulfur is the primary constituent that lowers the grade and thus has been studied extensively. Sulfur in coal lowers the quality of iron and steel, causes corrosion and deposits, and promotes air pollution. Sulfur ranges between 0.2 to 7.0 percent by weight, with the average being between 1 and 2 percent. Sulfur occurs as inorganic pyrite and marcasite ( 40 to 80 percent) with the balance contained in the organic structure. The highest sulfur coals are the bituminous coals of the Pennsylvanian age in the Appalachian, Illinois, and Western Interior coal basins. The lowest sulfur coals are the subbituminous coals and lignites in the Rocky Mountain and Northern Great Plains Regions. These coals contain less than 1 percent sulfur. The molecular structure of coal is not completely known. Investigators (Solomon. Wisner, and Heredy and Wender) ${ }^{2}$ have gathered information from infrared measurements, nuclear magnetic resonances, ultimate and proximate analyses, and pyrolysis data to obtain models for the chemical structure of the organic backbone of coal. This organic backbone of coal is constructed of aromatic and hydro-aromatic units. Some of these units have various functional groups that cross-link the units together. The planar nature of the aromatics gives the coal a layered consistency. The layers may be twisted in such a way that a perfect laminate is not obtained. The imperfection in the laminate creates pores that may house ash or other impurities. Low rank coals have about 90 percent of the carbon associated with 5-unit layers, while high rank coals have about 90 percent of the carbon associated in 30-unit layers. ${ }^{1,2,3,4}$

\section{Devolatilization}

Coal devolatilization has been studied widely, and many models have been developed. ${ }^{1}$ The models reviewed are limited to coal particles less than or equal to $100 \mu \mathrm{m}$. These models are categorized as: (1) single reaction, (2) multiple parallel reactions, (3) multiple competing reactions, (4) complex schemes, and (5) schemes involving secondary char formation. These models vary from the very simple to the very complex. The details of these models are discussed below.

For the single reaction, coal $\rightarrow$ solid + volatile, the reaction rate models are simple and quite limited. Both an Arrhenius expression: 


$$
\frac{d V}{d t}=k\left(v_{\infty}-v\right)^{n}
$$

and a non-Arrhenius expression

$$
\frac{\mathrm{dV}}{\mathrm{dt}}=B V_{\infty} / \mathrm{t}
$$

have been developed. The order $\mathrm{n}$ in the Arrhenius expression has been estimated to be between 1 and 8 , depending on the investigator. The non-Arrhenius expression neglects the observed temperature dependence on devolatilization.

The second category consists of multiple parallel reactions that are firstorder Arrhenius expressions. This category has been subdivided by Ubhayakar ${ }^{1}$ into two sections, namely, two first-order Arrhenius models and multiple first-order reactions with a statistical distribution of the activation energy. The devolatilization process is modeled by the first of these techniques by the following set of equations:

$$
\begin{aligned}
& \mathrm{C}_{1} \stackrel{\mathrm{kl}}{\rightarrow} \mathrm{S}_{1}+\mathrm{V}_{1} \\
& \mathrm{C}_{2} \stackrel{\mathrm{k} 2}{\rightarrow} \mathrm{S}_{2}+\mathrm{V}_{2}
\end{aligned}
$$

where:

$$
\frac{\mathrm{d} \mathrm{C}_{1,2}}{\mathrm{dt}}=-\mathrm{k}_{1,2} \mathrm{C}_{1,2}
$$

The second technique is described by the equations below:

$$
\text { Coal }=\sum_{i=1}^{n} C_{1} \stackrel{k i}{\rightarrow} \sum_{i=1}^{n}\left(S_{i}+V_{i}\right) \rightarrow S+V
$$

where:

$$
\begin{gathered}
\frac{d V_{1}}{d t}=k i\left(V_{i, \infty}-V_{i}\right) \\
k_{i}=A \exp \left(-E_{i} / R T\right) \\
\int_{0}^{\infty} r(E) d E=1
\end{gathered}
$$

Equation (3.8) gives a complete statistical distribution of activation energy. 
Multiple competing reaction models, the third category, are also used to express the devolatilization process. In this category, the devolatilization reaction is expressed:

$$
\begin{gathered}
k_{1}\left(1-Y_{1}\right) \text { Char }+Y_{1} V_{1} \\
\text { Coal } k_{2}\left(1-Y_{2}\right) \text { Char }+Y_{2} V_{2} \\
k_{n} k_{n}\left(1-Y_{n}\right) \text { Char }+Y_{n} V_{n}
\end{gathered}
$$

with two rate equations

and

$$
\frac{d(\text { coal })}{d t}=-\left(\sum_{i=1}^{n} k_{i}\right) \text { Coal }
$$

$$
\frac{d V}{d t}=\left(\sum_{i=1}^{n} Y_{i} V_{i}\right) \text { Coal }
$$

Kobayashi ${ }^{1,2}$ used this model with $n=2$. Smith and Smoot ${ }^{2}$ applied this model in their pulverized coal combustion and gasification models with good success.

The fourth category, complex schemes, includes the multiple consecutive parallel first-order reaction:

$$
\begin{aligned}
& \text { Coal } \stackrel{k_{1}}{\rightarrow} \text { metaplast } \stackrel{k_{2}}{\rightarrow} \text { residue } \stackrel{k_{4}}{\rightarrow} \text { primary tar } \\
& \mathrm{k}_{3} \quad \mathrm{k}_{5} \mathrm{~L}_{+}^{\text {secondary }}+\mathrm{gar} \\
& \text { semi-coke + gas } \\
& k_{r}-\text { coke + gas }
\end{aligned}
$$

and the parallel competing first order reaction:

$$
\text { Coal } \stackrel{k_{1}}{\rightarrow} \text { Activated Coal } \frac{k_{2}}{k_{3}} \text { methane and ethane }
$$

These two mechanisms are complicated, producing several intermediate and final products. A coal combustion model needs a simple. straightforward model of the devolatilization process. These two models do not provide these criteria. 
The final category, schemes involving secondary char-forming reactions, contains two models: (1) consecutive competing char-forming reactions and (2) parallel competing char-forming reactions. These models are too complex to be included in a combustor model. The first has seven reactions, producing seven product types, while the second has $n+2$ reactions and a statical distribution of activation energies.

The models presented above indicate that the fraction of volatile matter evolved is a function of both the temperature and the length of time for which devolatilization occurs. For bituminous coals, Kobayashi et al. ${ }^{2}$ report that at a temperature of $1260^{\circ} \mathrm{K}$ and for a time of 200 milliseconds, 30 percent of the coal is volatilized.

\section{Char Oxidation}

The devolatilization process produces a solid residue, char. The char consists of the fixed carbon and ash. In actuality, the char is a composite material containing carbon, hydrogen, sulfur, oxygen, nitrogen, and ash. An ultimate analysis of the char shows that the fractions of each of these elements in general are in approximately the same ratios as in the parent coal. Char oxidation is a heterogeneous chemical reaction. These reactions have been studied extensively, 5 and the reaction mechanism developed in those studies is discussed below.

\section{Heterogeneous Char Reactions}

Char consists of three major elements: carbon, hydrogen, and sulfur, which are oxddized. The general heterogeneous chemical reaction is expressed as:

$$
A_{\text {gas }}+b_{\text {solid }} \stackrel{k}{\rightarrow} \text { products }
$$

Written in this manner, the reactions for carbon, hydrogen, and sulfur become:

$$
\begin{gathered}
\mathrm{O}_{2}+2 \mathrm{C} \rightarrow 2 \mathrm{CO} \\
\mathrm{O}_{2}+\mathrm{C} \rightarrow \mathrm{CO}_{2} \\
\mathrm{O}_{2}+4 \mathrm{H} \rightarrow 2 \mathrm{H}_{2} \mathrm{O} \\
\mathrm{O}_{2}+\mathrm{S} \rightarrow \mathrm{SO}_{2}
\end{gathered}
$$


This group of reactions is a simplification of possible reactions that have been researched and shown to exist in minor amounts. ${ }^{1}$

Smith has reviewed the question as to which product is favored - $\mathrm{CO}$ or $\mathrm{CO}_{2}$ - and suggests that $\mathrm{CO}$ is the most likely. ${ }^{2}$

\section{Kinetics of Heterogeneous Char Oxidation}

Heterogeneous chemical reactions have also been studied extensively. Levenspiel ${ }^{5}$ has proposed a mechanism for gas-solid reactions that has withstood numerous investigations and applications. Heterogeneous reactions are envisioned to proceed by the following steps:

(1) Diffusion of reactant gas from the bulk fluid through the gas film surrounding the particle to the solid surface.

(2) Penetration and diffusion of reactant gas through a blanket of ash (solid producl) to the unreacted core.

(3) Chemical reaction of reactant gas with solid at the reaction surface.

(4) Diffusion of the product gas through the gas to the exterior surface of the particle.

(5) Diffusion of the product gas through the gas film surrounding the particle to the bulk fluid.

One or all of these steps may be involved in the chemical reaction sequence. The steps that offer the greatest resistance to the propagation of the reaction are called the rate controlling steps. For reactions such as char oxidation in which a stationary ash layer is not formed. Steps 2 and 4 have negligible resistances and can be neglected. The driving force for the product gas between the surface and the bulk fluid is in general quite large since the bulk contains little or no product gas. Thus. Step 5 offers negligible resistance and is neglected.

The rate of chemical reaction for the general reaction with Steps 1 and 3 controlling is given by:

$$
R=\frac{\mathrm{dm}_{\mathrm{B}}}{\mathrm{dt}}=\frac{\mathrm{AbM_{B }} \mathrm{C}_{\mathrm{A}}}{\frac{1}{k_{\mathrm{c}}}+\frac{1}{k_{\mathrm{d}}}}
$$


The two terms, $1 / k_{c}$ and $1 / k_{d}$, are the chemical reaction resistance and the mass transfer resistance, respectively. The chemical reaction rate constant. $k_{c}$, has been studied extensively for the carbon-oxygen reaction. ${ }^{1,2}$ However, reaction rate constants for the hydrogen-oxygen and sulfur-oxygen reactions are not avallable in published literature. The mass transfer coefficient, $k_{d}$, has been studied extensively for a single particle in a fluid. ${ }^{5}$

The reaction rate coefficient, $k_{c}$, for the carbon-axygen reaction has been well studied by investigators ${ }^{2}$ using the conventional Arrhenius expression $k=A$ exp $(-E / R T)$ to model the effect of reaction temperature. Table 3.1 summarizes the values for the frequency factor $A$, and activation energy $E$, along with the type of coal char and particle size used in the experiment. As can be seen in Table 3.1, the type of coal char greatly influences the values of the frequency factor and activation energy.

The mass transfer coefficient is expressed:

$$
\mathrm{k}_{\mathrm{d}}=\frac{\operatorname{Sh} \mathrm{D}}{\mathrm{d}_{\mathrm{p}}}
$$

The Sherwood Number, Sh, is modeled by:

$$
\mathrm{Sh}=2+0.6 \mathrm{Re}^{1 / 2} \mathrm{Sc}^{1 / 3}
$$

The Sherwood Number or the mass transfer coefficient modeled by these equations shows good agreement with the experimental data and is an accepted approach to modeling the mass transfer resistance.

\section{Volatile Matter Oxidation}

Experimental information on the volatile oxidation rate has not been found in the literature. Experimental research in this area is needed to verify the theoretical predictions. ${ }^{1,2}$ Volatile product combustion times are estimated by considering only mass transfer resistances and chemical reaction rate resistances. ${ }^{3}$ The burning time, assuming the volatiles have a molecular weight of 100 and the coal has a volatile fraction of 0.5 , is 7 milliseconds for a $50-\mu \mathrm{m}$ coal particle at $1273^{\circ} \mathrm{K}$. If the mass transfer resistance is negligible, such that only the chemical reaction is considered and assuming the reaction rate to be that for $\mathrm{CO}$ going to $\mathrm{CO}_{2}$ (the slowest step). the combustion lime can be estimated. These assumptions provide only an order of magnitude value. The burning time for a $50-\mu \mathrm{m}$ particle at $1273^{\circ} \mathrm{K}$ is 3.2 milliseconds. These two burning time values are approximately the same, such that the volatile oxidation process is neither only diffusion controlled nor reaction rate controlled. 
TABLE 3.1

CARBON-OXYGEN REACTION RATE CONSTANTS, $k_{p}$ where $k p=\frac{k_{c} M_{O_{2}}}{T_{g} R}=A \exp (-E / R T)$

\begin{tabular}{|c|c|c|c|}
\hline $\begin{array}{l}\text { Type of } \\
\text { Coal Char }\end{array}$ & $\begin{array}{c}\text { Particle } \\
\text { Size }\end{array}$ & $\begin{array}{l}\text { Frequency } \\
\text { Factor }\end{array}$ & $\begin{array}{c}\text { Activation } \\
\text { Energy }\end{array}$ \\
\hline$(\mu \mathrm{m})$ & & $\left(o_{2}\right)$ & $\left(\frac{k_{c a l}}{k_{\text {gmol }}}\right)$ \\
\hline $\begin{array}{l}\text { Bituminous } \\
\begin{array}{r}38 \\
82 \\
105\end{array}\end{array}$ & 28 & 92 & 21,900 \\
\hline $\begin{array}{l}\text { Non-Swelling } \\
\text { Bituminous }\end{array}$ & $\begin{array}{l}27 \\
38\end{array}$ & $\begin{array}{l}45.7 \\
80.3\end{array}$ & $\begin{array}{l}17,263 \\
21,787\end{array}$ \\
\hline $\begin{array}{l}\text { Swelling } \\
\text { Bituminous }\end{array}$ & $\begin{array}{l}31 \\
72\end{array}$ & $\begin{array}{l}94.3 \\
1000\end{array}$ & $\begin{array}{l}23,463 \\
35,194\end{array}$ \\
\hline $\begin{array}{l}\text { Anthracites } \\
\text { and } \\
\text { Semi-Anthracites }\end{array}$ & $\begin{array}{l}23 \\
78\end{array}$ & 20.4 & 19,000 \\
\hline Flash Pyrolysis Char & 85 & 16.3 & 17,597 \\
\hline Petroleum Coke & - & 15 & 19,000 \\
\hline
\end{tabular}




\section{Soot Oxidation}

The oxidation time for soot has been estimated. ${ }^{3}$ For a soot particle with a $500 \mathrm{~A}^{\circ}$ diameter the combustion time is $0.173 \mathrm{~s}$ at a temperature of $1600^{\circ} \mathrm{K} .^{3}$ Lee, Thring, and Beer ${ }^{3}$ obtained the following expression for the soot combustion rate:

$$
r=1.085 \times 10^{4} \mathrm{P}_{\mathrm{O}_{2}} \mathrm{~T}^{1 / 2} \exp (-39300 / \mathrm{RT})[=] \frac{\mathrm{g}}{\mathrm{Cm}^{2} \mathrm{~s}}
$$

for $400 A^{\circ}$ soot particles.

\subsubsection{Slurry Handling}

The in-house handling of CWF will typically consist of pumping CWF to the atomizer, piping, and cleaning systems.

\section{Pumping}

The pumping of the CWF is of critical concern since the CWF fuels are abrasive and exhibit complex rheological behavior. Depending on the shear rates, the CWF can have pseudoplastic, dilatant, or Newtonlan shear stress/shear rate behavior. The low solids CWF (50 to 60 percent) generally exhibit Newtonian behavior for shear rates magnitudes comparable to handling systems and do not require the same concern for fuel handing. ${ }^{1,2}$ In general, pumping system design has to avoid high shear rates and must match the pumping velocities to the type of fuel used.

The rheology of CWF depends strongly on coal type, extent and method of beneficiation, solids content, particle size distribution, and additives used in the formulation, as well as time. Initially, the CWF's show a reduction in viscosity, ${ }^{7}$ the magnitude of which is based on the additive levels and particle size distribution.

After the initial reduction, and especially for heavily loaded slurries, the viscosity remains constant at a particular shear rate until the accumulated amount of shear increases to the design point. Once this level of shear is reached, the viscosity of the fuel gradually increases and a yield point forms. This viscosity continues to increase with accumulated shear until the fluid is no longer pumpable. If a sample of this CWF were tested, it would exhibit a completely different shear stress/shear rate behavior from its original rheogram. There are many causes for this behavior: comminution, deagglomeration, additive evaporation, or changes in the zeta potential. ${ }^{7}$ 
Three types of pumps have been used for CWF: progressing cavity pump, diaphragm pump, and centrifugal pump. Most of the CWF industry has centered on the use of progressing cavity pumps since they develop low shear rate, have minimal or no wear problems, and have a wide selection of flow rate and discharge pressures. Materials compatible with CWF's include modular iron, carbon steel, stainless steel, Buna $\mathrm{N}$, and various polymer compounds.

In general, progressing cavity pumps are highly suitable for handling CWF. ${ }^{8}$ They have predictable performance and pulsationless discharge. Erosion is kept to a minimum by the use of elastomers for the outer stationary gear. Also, the compression fit between the elastomeric stator and rotor makes the pump capable of pumping high viscosity and abrasive CWF's. Progressing cavity pumps have been used extensively and successfully in government research facilities, industrial trial combustion tests, and in commercial slurry producers' plants, both in the United States and abroad. Most of the pumping of the highly loaded CWF, however, has not been continuous so far.

Centrifugal pumps have high internal shear rates and, thus, accelerate the alteration of CWF properties. ${ }^{8}$ CWF behavior is affected more dramatically in cases of highly loaded CWF, as compared to pumping moderately loaded CWF. Thus, the CWF formulation (with respect to the combination of particle size distribution. interaction of chemical dispersant, and stabilizers) greatly affects the performance of the centrifugal pumps. In view of these limitations, centrifugal pumps are not suitable for residential furnace applications.

Another type of pump that has been used for pumping CWF in residential furnace applications is the peristaltic pump. ${ }^{9}$ Because of the manner in which it operates, the peristaltic pump offers several advantages over the progressing cavity and centrifugal pumps. First, none of the mechanical parts of the pump come in contact with the CWF. This eliminates any wear problems associated with the pump as a result of the abrasive nature of CWF. Second, because of the positive displacement nature of the pump, it can be calibrated and used as a metering pump to measure the flow rate of the CWF being burned. These pumps are much less expensive than progressing cavity pumps, and the only maintenance they require is the replacement of pump head tubing after about 1,000 to 1,500 hours of operation. Finally, the peristaltic pumps are available in very small capacities as required for residential applications; therefore, there is no need for recirculation of the excess CWF back to the storage tank. ${ }^{7}$

Should the CWF characteristics require recirculation for keeping the coal in suspension, a peristallic pump with multiple heads can be installed on the same drive shaft, as shown in Figure 3.1. In this arrangement, the pumps can be sized for slurry recirculation and the amount of CWF needed for atomization. 


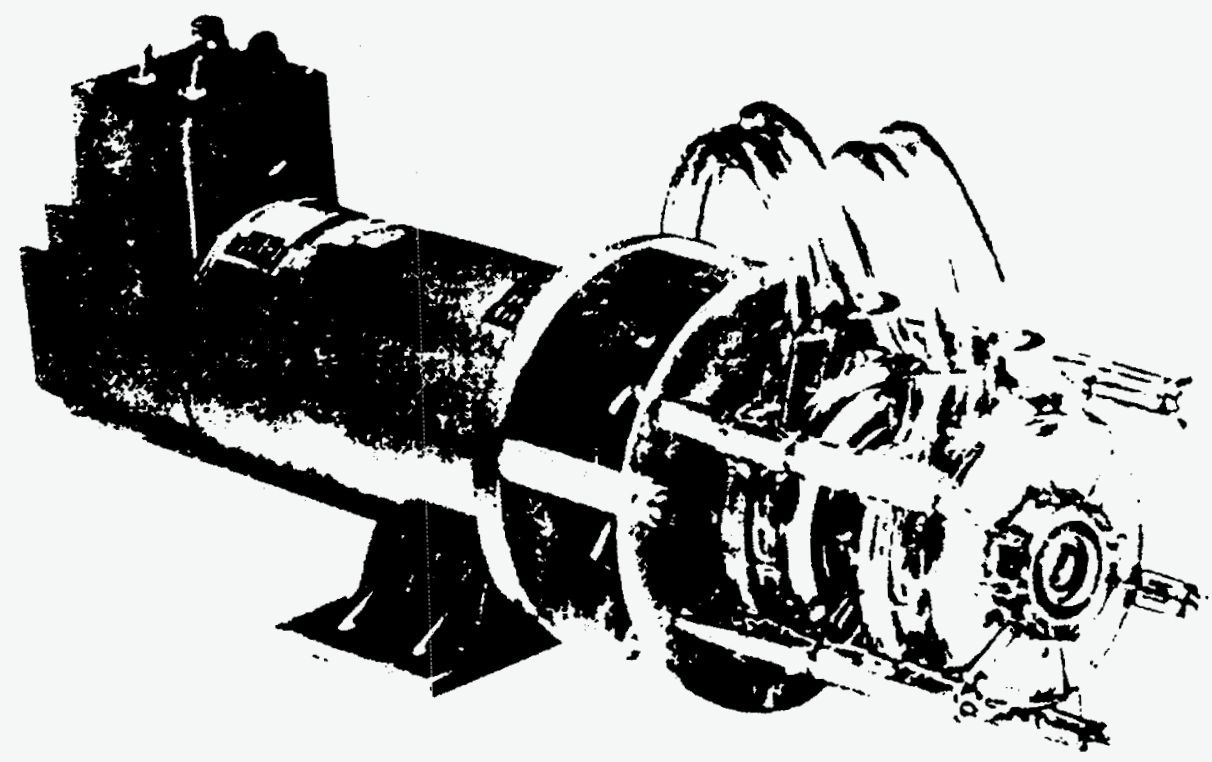

Figure 3.1 Peristaltic Pump with Dual Pump Heads 


\section{Piping}

By designing the piping for laminar flow, the shear rate in the piping is kept low. At higher velocilies, the differential pressures are too great and may also lead to erosion problems. The design of valve pressure drops should also be kept low to minimize erosion. For pipe sizing, Newtonian assumptions are used with standard design equations.

To minimize settling problems, all of the piping is pitched, piping dead-legs are avoided, and rod-out ports are used at branch points. The piping system is provided with a water hushing or cleaning system for removal of residual fuel in the lines. Although the inherent stability of the CWF will allow the slurry to be pumped to the atomizer without the need for flushing during routine operation, during extended outages the water flushing system is operated to avoid buildup of CWF in the piping system.

\subsubsection{NO $x$ Reduction}

Slurry-fueled systems have a number of advantages over dry pulverized coal systems in controlling $\mathrm{NO}_{x}$ emissions ( $\mathrm{NO}$ and $\mathrm{NO}_{2}$ ). Lower operating temperatures significantly reduce the amount of $\mathrm{NO}_{\mathrm{x}}$ produced by oxidation of the nitrogen in the combustion air (often referred to as "thermal $\mathrm{NO}_{\mathrm{x}}$ ").

However, in coal-fired systems as much as three-quarters of the $\mathrm{NO}_{\mathbf{x}}$ results from the oxidation of fuel-bound nitrogen (or "fuel- $\mathrm{NO}_{x}$ "). Fuel-NO $\mathrm{N}_{\mathrm{x}}$ formation appears to depend on the local avallability of oxygen during combustion, the complex evolution of intermediate nitrogenous radical species, and coal properties such as volatility. Meeting future stringent $\mathrm{NO}_{\mathrm{x}}$ emissions limits without relying on post-combustion controls will require effective control on chemistry of fuelbound nitrogen.

Figure 3.2 simplistically demonstrates the pathway in which fuel nitrogen converts to $\mathrm{NO}$ and $\mathrm{NO}_{2}$. Pyrolysis produces volatile nitrogen species, primarily in the amine and cyanide groups. These in turn undergo oxidation and thermal degradation, producing $\mathrm{NO}$ and $\mathrm{NHI}(1=1,2,3)$ species. The char nitrogen is oxidized to NO. The NO is reduced to $\mathrm{N}_{2}$ by reaction with $\mathrm{CO}, \mathrm{CaSO}_{3}, \mathrm{C}$, or $\mathrm{NH}_{3}$. These reactions are given in Table $3.2 .^{9,10,11}$

The first four reactions shown in Table 3.2 are the nitrogen oxide generating reactions. Oxidation of the fuel nitrogen is an essential step in the mechanism transforming fuel-bound nitrogen to $\mathrm{N}_{2}$ molecule. Careful control of the stoichiometry in this initial region where pyrolysis occurs and NO production begins will provide an abundance of chemical species able to reduce the NO to $\mathrm{N}_{2}$ by consuming oxygen. 


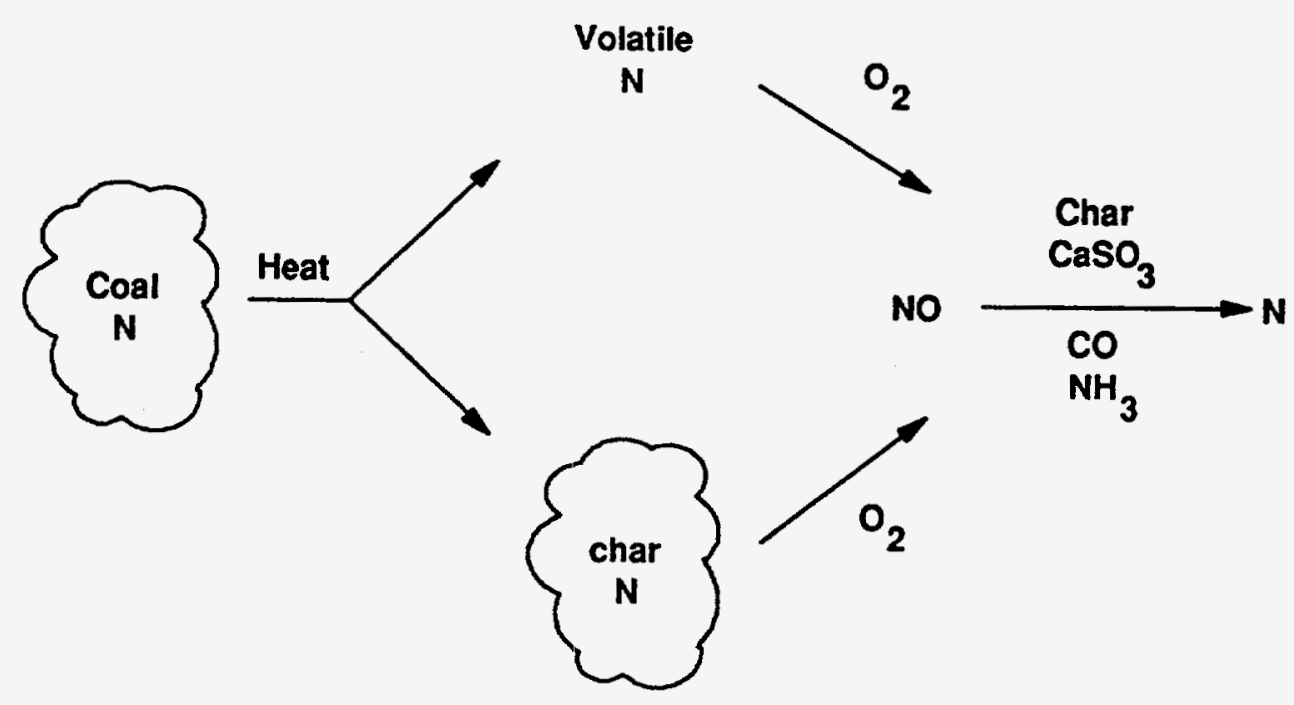

Figure 3.2 Nitrogen Pathway 
TABLE 3.2

CHEMICAL REACTIONS INVOLVING FUEL NO FORMATION AND DESTRUCTION

\begin{tabular}{|c|c|}
\hline $\begin{array}{l}\text { Reaction } \\
\text { Number }\end{array}$ & Reaction \\
\hline 1 & Coal + heat $\rightarrow$ volatile $N+$ char $N$ \\
\hline 2 & Volatile $\mathrm{N}+\mathrm{O}_{2} \rightarrow \mathrm{NO}+\mathrm{NH}_{3}$ \\
\hline 3 & $\operatorname{CharN}+\mathrm{O}_{2} \rightarrow \mathrm{NO}$ \\
\hline 4 & $\mathrm{NH}_{3}+5 / 4 \mathrm{O}_{2} \rightarrow \mathrm{NO}+3 / 2 \mathrm{H}_{2} \mathrm{O}$ \\
\hline 5 & $\mathrm{NO}+\mathrm{C} \rightarrow \mathrm{CO}+1 / 2 \mathrm{~N}_{2}$ \\
\hline 6 & $\mathrm{NO}+\mathrm{CO} \rightarrow \mathrm{CO}_{2}+1 / 2 \mathrm{~N}_{2}$ \\
\hline 7 & $\mathrm{NO}+2 \mathrm{NH}_{3}+\mathrm{O}_{2} \rightarrow 3 \mathrm{H}_{2} \mathrm{O}+3 / 2 \mathrm{~N}_{2}$ \\
\hline 8 & $\mathrm{NO}+\mathrm{CaSO}_{3} \rightarrow \mathrm{CaSO}_{4}+1 / 2 \mathrm{~N}_{2}$ \\
\hline 9 & $\mathrm{NO}+1 / 2 \mathrm{O}_{2} \rightarrow \mathrm{NO}_{2}$ \\
\hline
\end{tabular}


Staged combustion provides a chemical environment favorable to NO reduction by supplying a relatively high concentration of unoxidized carbon in the char, carbon monoxide, ammonia, and calcium sulfite (where calcium oxide is used to control $\mathrm{SO}_{2}$ emissions). It should be pointed out for clarity, however, that NO is produced throughout the combustor from oxidation of the nitrogen in the char.

Researchers have shown that the reduction of NO by oxidizing the other reactant in reactions 5 through 8 progresses at rates approximately $2 / 3$ as fast as

oxidation with $\mathrm{O}_{2} \cdot{ }^{9,10}$ Reaction 9 shows the conversion of $\mathrm{NO}$ to $\mathrm{NO}_{2}$, producing a mixture of $\mathrm{NO}$ and $\mathrm{NO}_{2}$ referred to as $\mathrm{NO}_{x}$. This mechanism has been used to predict $\mathrm{NO}_{\mathrm{x}}$ formation from an industrial steam generator ${ }^{12}$ with good results.

\subsubsection{Sulfur Dioxide Removal}

\section{Desulfurization}

The introduction of the Clean Adr Act has nurtured the development of sulfur dioxide removal processes. Both wet and dry techniques have been developed to date, with wet processes dominating the market. These processes are expensive to manufacture and operate. Dry processes such as limestone injection systems and fluidized bed coal combustion in a limestone bed are both being researched.

Dry sulfur dioxide removal processes utilize the following chemical overall reaction.

$$
\mathrm{CaO}+\mathrm{SO}_{2}+1 / 2 \mathrm{O}_{2}=\mathrm{CaSO}_{4}
$$

The reaction proceeds forward at temperatures up to $1500^{\circ} \mathrm{K}$ for sulfur dioxide concentrations of approximately $3000 \mathrm{ppm} .{ }^{13}$ The calcium oxide is generated by the calcination of limestone $\left(\mathrm{CaCO}_{3}\right)$ and dolomite $\left(\mathrm{CaCO}_{3} / \mathrm{MgCO}_{3}\right)$. The calcium oxdde and magnesium oxide oblained by calcination are both capable of sulfinating. Formulation of magnesium sulfate occurs at temperatures below $1110^{\circ} \mathrm{K}$. However. experimental evidence shows the reaction to occur only slightly in the 700 to $970^{\circ} \mathrm{K}$ temperature range. ${ }^{13}$

The sulfination reaction rate has been found to decay with time. This phenomenon is explained by the observation that pores are created in the stone structure by the calcination process. The actual decay in rate is attributed to the substitution of the much larger suifur trioxide molecule for the carbon dioxide molecule. Researchers have taken two approaches in modeling this phenomenon. Some have used a simple exponential decay models ${ }^{13,14,15}$ while others have used 
complicated grain models. ${ }^{16,17}$ The grain models are more theoretical in nature and probably describe the actual decay phenomenon as it truly is. However, the grain models' complexities limit their use in a combustion process model.

Borgwardt ${ }^{13}$ has conducted extensive experimental studies on stone sulfination. He modeled the reaction rate time delay phenomenon by modifying the conventional Arrhenius frequency factor. Borgwardt presented the following model:

$$
R=\frac{\eta}{\rho_{s}} A O \mathrm{e}^{-\beta \eta / / w} \mathrm{e}^{-\mathrm{E} / \mathrm{RT}} \mathrm{C}_{\mathrm{SO}_{2}}^{\mathrm{m}}
$$

He presents a method to obtain $\beta$, the exponential decay coefficient.

Lee ${ }^{14,15}$ has developed a simple model, based on two experimental parameters, which predicts the time decay quite well. This model is discussed below. The rate of reaction is expressed by the product of the initial rate and an exponential decay term.

$$
R=R_{0} e^{-t / \tau} p
$$

The exponential decay term contains the pore plugging time constant, $\tau_{\mathrm{p}}$, which is taken as one third the pore plugging time.

$$
\tau_{p}=\frac{t_{p}}{3}
$$

The pore plugging time has been shown to be inversely proportional to the sulfur dioxide concentration, thus $\tau_{p}$ can be expressed by:

$$
\tau_{\mathrm{p}}=\frac{\mathrm{p} *}{\mathrm{C}_{\mathrm{SO}_{2}}}
$$

where $P^{*}$ is the pure plugging constant. The initial rate, $R_{0}$ is expressed by:

$$
R_{o}=\frac{\pi d_{p}^{3}}{6} \rho_{s} k S \eta C_{S O_{2}}
$$


The group $\rho_{\mathrm{s}} \mathrm{kS} \eta$ is combined into one constant, $\tau_{\mathrm{SF}}$, which has been provided for a number of limestone and dolomite stones. Upon substituting, Lee obtained the following equation:

$$
\mathrm{R}=\frac{\pi \mathrm{d}_{\mathrm{p}}^{3}}{6} \frac{\mathrm{C}_{\mathrm{SO}_{2}}}{\tau_{\mathrm{SF}}} \mathrm{e}^{\left(-\mathrm{tC}_{\mathrm{SO}_{2}} / \mathrm{P}_{*}\right)}
$$

The only parameters needed from experimental data are $\mathrm{P}^{*}$ and $\tau_{\mathrm{SF}}$. Lee provided these data ${ }^{14}$ and conducted all experimental work using $1000 \mu \mathrm{m}$ particles.

The performance predicted by these models, particularly Borgwardt's model, agrees nicely with experimental data. ${ }^{18,19}$ Only a 3.5-percent deviation was obtained between predicted and experimental results for an industrial scale steam generation unit. This shows that the Borgwardt reaction model is usable in an engineering model of a desulfurization reactor.

\subsection{TASK 3.1 - ANALYTICAL MODELING}

In developing an analytical model of the $\mathrm{SO}_{2}$ reactor, several complexities are encountered due to the coupling of the flow fleld in the main body of the reactor to that of the axial recirculation loop. These two highly coupled flow fields result in the need to solve a three-dimensional, highly nonisotropic turbulent flow field with a dispersed second phase of particles that undergo chemical reactions.

One possible approach to modeling the reactor is to use available computational fuid dynamics (CFD) computer codes. Several codes are commercially avallable; however, each has limitations when applied to modeling the $\mathrm{SO}_{2}$ reactor. The turbulent flow field within the reactor is nonisotropic and as such, the standard two-equation $\mathrm{k}-\varepsilon$ model used in most codes is not the best representation of the turbulence within the reactor. In order to more accurately model the flow within the reactor, an algebraic stress model (ASM) should be used. A survey of codes that are commercially available shows that codes that have ASM turbulence models are not capable of accurately modeling the reactor geometry due to the recirculation line. The codes that are avallable that can handle the reactor geometry are typically limited to using the two-equation $\mathbf{k}-\varepsilon$ model, which is not the best choice for this problem.

In addition to the problems of geometry and turbulence models, the use of CFD codes to model the process inside the reactor can require a considerable computational effort. For example, it was estimated by a software vendor that in order to resolve the flow within a residential-sized $\mathrm{SO}_{2}$ reduction reactor. 
approximately 72,000 nodes would be required. In order to obtain a solution, the code must solve as a function of position within the reactor the three velocity components, pressure, a minimum of two turbulence parameters, particle trajectories, and chemical reactions with the gas and the particles. This can result in the need to solve more than 500,000 simultaneous, nonlinear equations, which is typically beyond the capabilities of engineering work stations for reasonable turnaround times.

As an alternative to the use of CFD codes, a simplified model of the reactor was developed. The purpose of this model was to determine the dominant parameters that govern the reduction of $\mathrm{SO}_{2}$ within the reactor, as well as to provide performance estimates under various operating conditions.

In developing the analytical model, one of the prime areas of concern is for given gas-now conditions, the ability of the reactor to detain particles of a given size. Though the flow within the reactor is quite complex, if the recirculation line effect is neglected, then the reactor is quite similar to a cyclone separator. The ability of cyclones to collect particles of a given size has been well documented, for example, by Zenz. ${ }^{(20)}$ For a given geometry and gas flow conditions the theoretically smallest-size particle size that a cyclone can collect, typically called the cut point diameter, can be found by:

$$
D p_{t h}=\left[\frac{9 \mu_{g} L_{w}}{\pi N_{s} v_{\text {in }}\left(\rho_{p}-\rho_{g}\right)}\right]^{\frac{1}{2}}
$$

where:

$\mu_{\mathrm{g}}$ is the gas viscosity

$v_{\text {in }}$ is the inlet velocity

$\rho_{\mathrm{p}}, \rho_{\mathrm{g}}$, are the particle and gas density, respectively

$\mathrm{N}_{\mathrm{s}}$ is the number of spiral turns, which is found from experiment

$\mathrm{L}_{\mathrm{w}}$ is the cyclone inlet width

For application of this equation to the axial recirculation reactor, $\mathrm{L}_{w}$ is defined as the radial distance between the reactor wall and the outside radius of the recirculation tube.

Once the cut point diameter is determined, the separation efficiency of any other size particle can be determined from normalized separation efficiency data, as shown by Zenz. ${ }^{(20)}$ With a knowledge of the separation efficiency of a given-size particle, its residence time in the reactor relative to the gas can be determined. 
Under steady-state conditions and assuming that the reactor is capable of fluidizing all the particles within it, as one particle is added to the reactor, one particle must leave. However, the particle that is added to the system will be recirculated $\mathrm{N}$ times before it leaves. The number of times a particle of a specific diameter within the reactor circulates. N. is dependent on the separation efficiency for this size particle. This relationship can be expressed as:

$$
N=1+\eta+\eta^{2}+\eta^{3}+\ldots
$$

where $\eta$ is the separation efficiency. This relation can be expressed in closed form as:

$$
\mathbf{N}=\frac{1}{1-\eta}
$$

Once $\mathrm{N}$ is determined, the amount of solid material in the reactor that can participate in the reduction of $\mathrm{SO}_{2}$ can be found since it is equal to $\mathrm{N}$ times the inlet solids flow rate.

With a knowledge of the amount of solids present in the reactor, one-dimensional species-continuity equations for the concentration of $\mathrm{SO}_{2}$ in the gas phase and $\mathrm{CaO}$ in the solid phase can be written as:

$$
\begin{aligned}
& \frac{\mathrm{d}\left[\mathrm{SO}_{2}\right]}{\mathrm{dZ}}=\frac{-6(1-\varepsilon)\left[\mathrm{SO}_{2}\right]}{\varepsilon \mathrm{D}_{\mathrm{p}} \mathrm{V}_{\mathrm{g}}\left(\frac{1}{\mathrm{k}_{\mathrm{c}}}+\frac{1}{\mathrm{k}_{\mathrm{d}}}\right)} \\
& \frac{\mathrm{d}[\mathrm{CaO}]}{\mathrm{dZ}}=\frac{-6\left[\mathrm{SO}_{2}\right]}{\mathrm{D}_{\mathrm{p}} \mathrm{V}_{\mathrm{s}}\left(\frac{1}{\mathrm{k}_{\mathrm{c}}}+\frac{1}{\mathrm{k}_{\mathrm{d}}}\right)}
\end{aligned}
$$

where

$\left[\mathrm{SO}_{2}\right]$ is the concentration of $\mathrm{SO}_{2}$ in the gas phase $[\mathrm{CaO}]$ is the concentration of $\mathrm{CaO}$ in the solid phase $\mathrm{V}_{\mathrm{g}}, \mathrm{V}_{\mathrm{s}}$ are the gas and solid phase velocities, respectively $\varepsilon$ is the void fraction (adjusted to account for particle recirculation) $k_{c}, k_{d}$ are the chemical kinetics and diffusion resistances, respectively $D_{p}$ is the particle diameter 
The diffusion resistance, $k_{d}$, can be found from the relationship:

$$
\mathrm{Sh}=2+0.6 \operatorname{Re}^{\frac{1}{2}} \mathrm{~S}_{\mathrm{c}}^{\frac{1}{3}}
$$

where:

$\mathrm{Sh}$ is the Sherwood number defined by:

$$
\operatorname{Sh}=\mathrm{k}_{\mathrm{d}} \frac{\mathrm{D}_{\mathrm{p}}}{D}
$$

$D$ is the diffusivity

Re is the Reynolds number based on the slip velocity

$\mathrm{Sc}$ is the Schmidt number

The chemical kinetics resistance is determined by using Borgwardt's model, which takes into account the decrease in the rate of reaction due to pore plugging:

$$
K_{c}=A_{o} \exp \left(-\beta \frac{n^{\prime}}{w}\right) \exp \left(-\frac{E}{R T}\right)
$$

where:

$A_{0}$ is the frequency factor

$\mathrm{n}^{\prime}$ is the sulfate in the stone

$W$ is the weight of the solid sample

$R$ is the universal gas constant

$T$ is the absolute temperature

$E$ is the activation energy

$\beta$ is a stone-dependent constant determined by experiment

This set of coupled equations is solved numerically as a function of length in order to determine reactor performance.

\subsubsection{Parametric Investigation}

With the model established, a parametric investigation was conducted to determine which factors have a significant effect on the performance of the reactor. For this investigation, the conditions shown in Table 3.3 were considered. 
TABLE 3.3

$\mathrm{SO}_{2}$ MODEL PARAMETERS

\begin{tabular}{|c|c|}
\hline Operating Temperature & $1,650^{\circ} \mathrm{F}$ \\
\hline Excess Air & $20 \%$ \\
\hline Flring Rate & $\begin{array}{l}100,000 \text { to } 400,000 \mathrm{Btu} / \mathrm{hr} \\
\text { (Nominal: } 100,000 \mathrm{Btu} / \mathrm{hr} \text { ) }\end{array}$ \\
\hline Inlet $\mathrm{SO}_{2}$ Concentration & $\begin{array}{l}330 \text { to } 4,000 \mathrm{ppm} \\
\text { (typical of } 0.5 \text { to } 6 \% \text { sulfur coal, } \\
\text { Nominal: } 3,000 \mathrm{ppm} \text { ) }\end{array}$ \\
\hline Calcium to Sulfur Ratio & $\begin{array}{l}0.5: 1-5: 1 \\
\text { (Nominal: } 3: 1 \text { ) }\end{array}$ \\
\hline Reactor Diameter & $4,6,8$ inches \\
\hline Reactor Height & $\begin{array}{l}0 \text { to } 100 \text { inches } \\
\text { (Nominal: } 50 \text { inches) }\end{array}$ \\
\hline $\begin{array}{l}\text { Limestone Properties } \\
\text { Activation Energy } \\
\text { Frequency Factor } \\
\text { Beta } \\
\text { Density } \\
\text { Particle Diameter }\end{array}$ & $\begin{array}{l}10,000 \mathrm{cal} . / \mathrm{g} \cdot \mathrm{mole} \\
335,000 \mathrm{l} / \mathrm{s} \\
333.33 \mathrm{~g} / \mathrm{g}-\mathrm{mole} \\
150 \mathrm{lbm} / \mathrm{tt}^{3} \\
10 \text { to } 1,000 \text { microns }\end{array}$ \\
\hline
\end{tabular}




\section{a. Effect of Particle Diameter}

The effect of particle diameter on reactor performance is shown in Figure 3.3 for reactor diameters of 4,6, and $8 \mathrm{in}$. For this case, the reactor height was chosen to be $50 \mathrm{in}$., the unit was operated at a gas flow rate equivalent to an input rate of $100,000 \mathrm{Btu} / \mathrm{hr}$, the concentration of $\mathrm{SO}_{2}$ was $3,000 \mathrm{ppm}$, and the $\mathrm{Ca} / \mathrm{S}$ ratio was 3:1. Figure 3.3 shows that for each different diameter reactor there is an optimum sorbent particle diameter that maximizes $\mathrm{SO}_{2}$ capture. For the conditions considered in this analysis, this corresponds to particle diameters of 30,75 , and 130 microns for reactor diameters of 4,6 , and 8 inches, respectively.

The fact that the model predicts an optimal particle diameter for a particular set of operating conditions can be attributed to the way in which the reactor operates. At particle diameters smaller than the optimal, a tremendous amount of sorbent surface area is available to participate in $\mathrm{SO}_{2}$ capture; however, since these particles are small and cannot be separated and detained effectively within the reactor, their ability to capture $\mathrm{SO}_{2}$ is not realized. At particle diameters above the optimal, performance again decreases, though not as rapidly for particles smaller than the optimal. The reason for the decrease is that these larger sized particles are easily separated and detained within the reactor. As the particle diameter is increased, however, its surface area relative to its volume is decreased. As a result, there is less surface area in the reactor relative to optimal conditions, and performance decreases.

In addition to each reactor diameter having an optimal particle diameter for $\mathrm{SO}_{2}$ capture, this particle diameter increases with increasing reactor diameter. This is due to the fact that smaller diameter reactors have higher separation efficiencies for smaller stzed particles. Even though the smaller diameter reactors are capable of separating smaller diameter particles and as such for a given $\mathrm{Ca} / \mathrm{S}$ ratio would have more avallable surface area within the reactor, their ability to capture $\mathrm{SO}_{2}$ is not as great as the larger diameter reactors. The reason for this is that for a fixed reactor height, the smaller diameter reactor would have a higher axial velocity and a shorter residence time within the reactor compared to larger diameter units for similar operating conditions.

\section{b. Effect of $\mathrm{SO}_{2}$ Concentration}

The effect of inlet $\mathrm{SO}_{2}$ concentration on reactor performance is shown in Figure 3.4. For this case, the reactor height was chosen to be $50 \mathrm{in}$., the unit was operated at a gas flow rate equivalent to an input rate of $100.000 \mathrm{Btu} / \mathrm{hr}$, and the $\mathrm{Ca} / \mathrm{S}$ ratio was $3: 1$. The concentration of $\mathrm{SO}_{2}$ was varied between 330 and $4,000 \mathrm{ppm}$, which is equivalent to coal with between 0.5 and 6 percent sulfur. Figure 3.4 shows that as the concentration is increased, the percent reduction in $\mathrm{SO}_{2}$ also increases. 
Predicted $\mathrm{SO}_{2}$ Reduction Reactor Performance

Input: 100,000 Btu/hr at 20 Percent Excess Air

Inlet Conc.: 3,000 ppm ( $\mathrm{Ca} / \mathrm{S}=3: 1)$

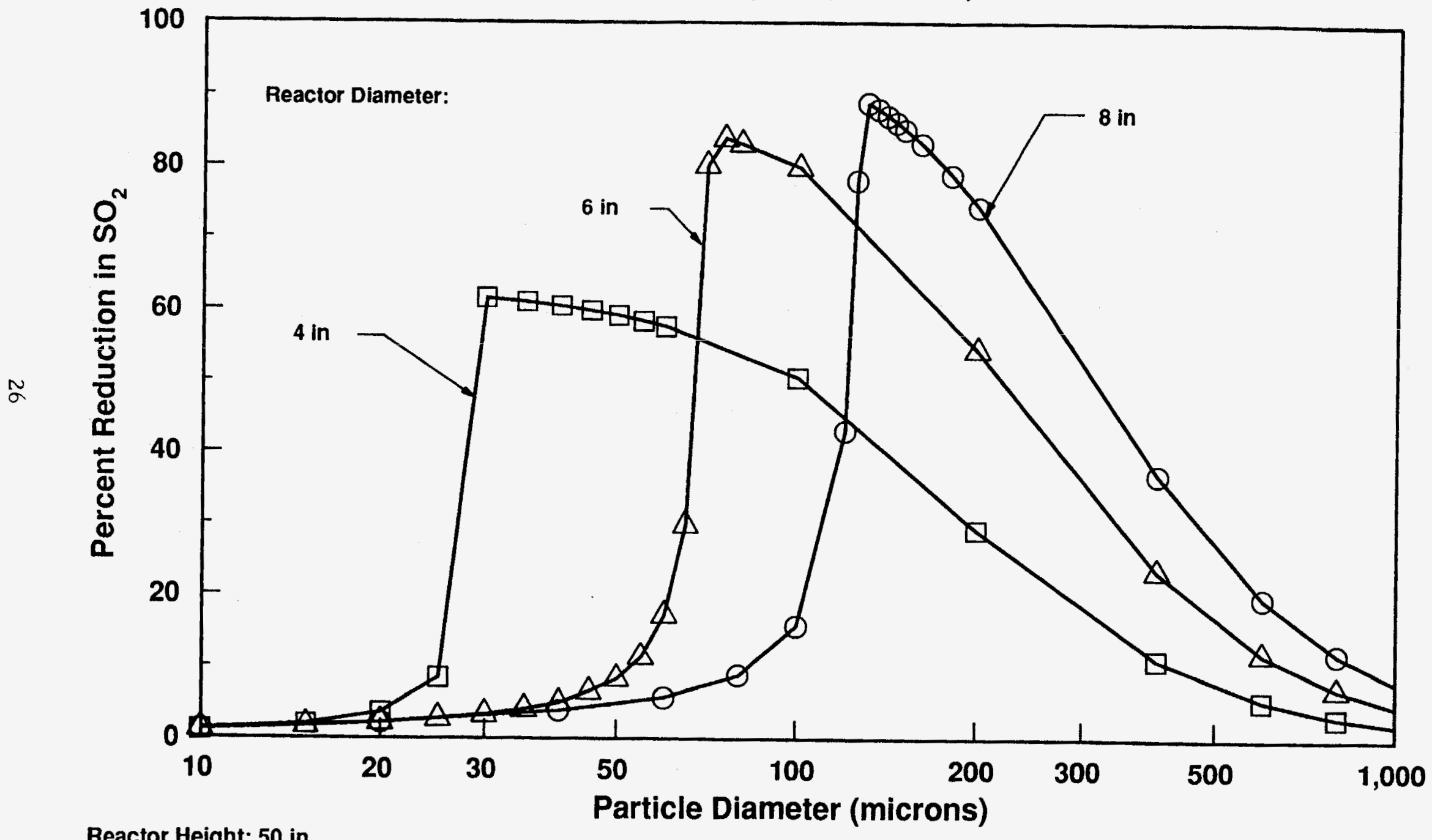

Reactor Height: 50 in.

Figure 3.3 Effect of Particle Diameter on Reactor Performance 
Predicted $\mathrm{SO}_{2}$ Reduction Reactor Performance

Input: 100,000 Btu/hr at 20 Percent Excess Air

Reactor Height: 50 in. $\mathrm{Ca} / \mathrm{S}=3: 1$

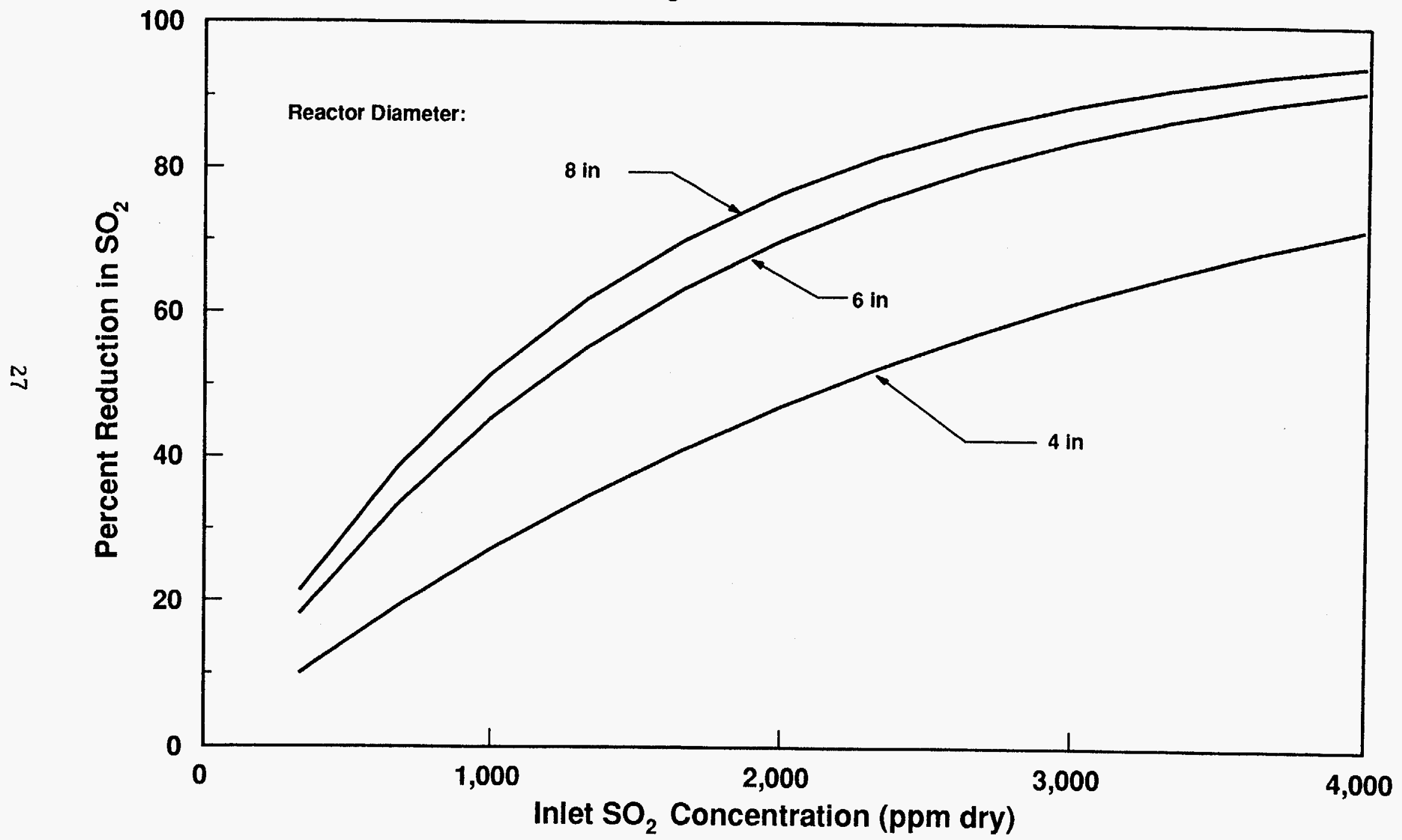

Figure 3.4 Effect of $\mathrm{SO}_{2}$ Concentration on Reactor Performance 
The reason for the increase in performance can be explained by referring to equation (3.33). For a fixed $\mathrm{Ca} / \mathrm{S}$ ratio, as the concentration is increased the term on the right hand side of the equation becomes a larger negative number since both concentration and effective solids loading are increasing. Thus there is a stronger gradient in $\mathrm{SO}_{2}$ concentration as a function of reactor length.

As illustrated in Figure 3.4, for a given $\mathrm{SO}_{2}$ concentration, as the reactor diameter increased reactor performance also increased. This is due to the increased residence time assoclated with the larger diameter reactors when they are operated with their optimum particle diameter (found in Figure 3.3).

\section{c. Effect of Calcium-to-Sulfur Ratio}

The effect of calcium-to-sulfur ratio $(\mathrm{Ca} / \mathrm{S})$ on reactor performance is shown in Figure 3.5. For this case, the reactor height was chosen to be $50 \mathrm{in}$., the unit was operated at a gas flow rate equivalent to an input rate of $100,000 \mathrm{Btu} / \mathrm{hr}$, and the concentration of $\mathrm{SO}_{2}$ was $3,000 \mathrm{ppm}$. For this case, each reactor diameter considered was operated at its optimum particle diameter (found in Figure 3.3).

As the $\mathrm{Ca} / \mathrm{S}$ ratio is increased, reactor performance also increases with the larger diameter reactors capable of removing more $\mathrm{SO}_{2}$ due to their longer gas residence times. For the 6- and 8-in. diameter reactors, as $\mathrm{Ca} / \mathrm{S}$ is increased, the gain in performance starts to level off at a much quicker rate than for the 4-in. diameter reactor. For example, consider increasing $\mathrm{Ca} / \mathrm{S}$ mole ratio from 3 to 4. For the 8-in. diameter reactor, the percent reduction in $\mathrm{SO}_{2}$ increases from 88.9 to 94.7 ; however, for the 4-in. diameter reactor, this increase is from 61.6 to 72.2 percent.

\section{d. Effect of Reactor Height}

The effect of reactor height (directly proportional to gas residence time) on reactor performance is shown in Figure 3.6. For this case, the unit was operated at a gas flow rate equivalent to an input rate of $100,000 \mathrm{Btu} / \mathrm{hr}$, the concentration of $\mathrm{SO}_{2}$ was $3,000 \mathrm{ppm}$, and the $\mathrm{Ca} / \mathrm{S}$ ratio was $3: 1$. For this case, each reactor diameter considered was operated at its optimum particle diameter. as found in Figure 3.3.

As reactor height is increased, performance increases due to the longer gas residence time within the reactor. Increasing reactor height for a given diameter reactor tends to increase performance to the point where it approaches an exponential limit. With the 8-in. diameter reactor, this limit is approached in a much shorter reactor than with the 4-in. unit. 
Predicted $\mathrm{SO}_{2}$ Reduction Reactor Performance

TF24-790 Input: 100,000 Btu/hr at 20 Percent Excess Air

Inlet Conc: 3,000 ppm (Reactor Height: 50 in)

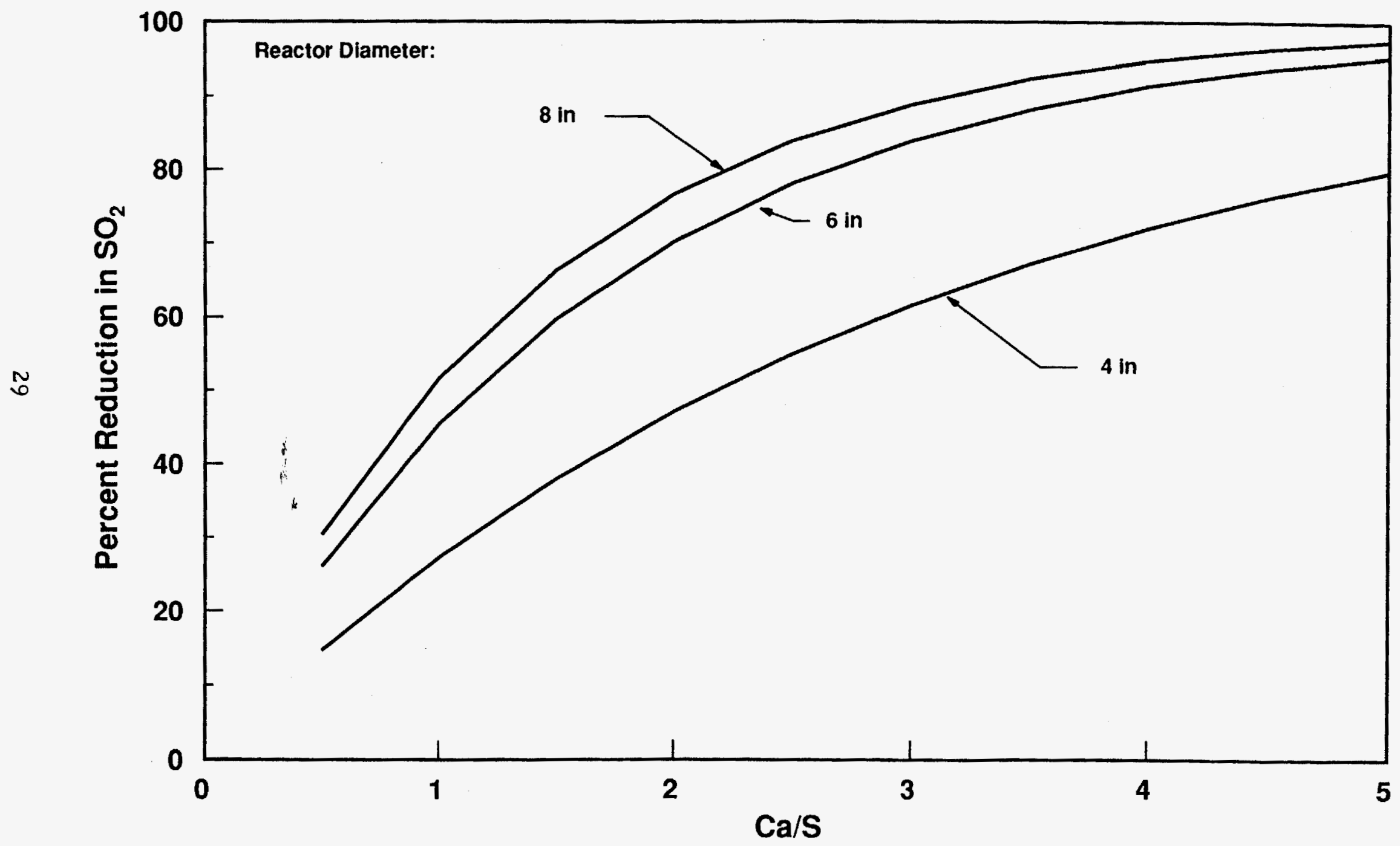

Figure 3.5 Effect of Calcium-to-Sulfur Ratio on Reactor Performance 
Predicted $\mathrm{SO}_{2}$ Reduction Reactor Performance

Input: 100,000 Btu/hr at 20 Percent Excess Air

Inlet Concentration: $3,000 \mathrm{ppm}, \mathrm{Ca} / \mathrm{S}=3: 1$

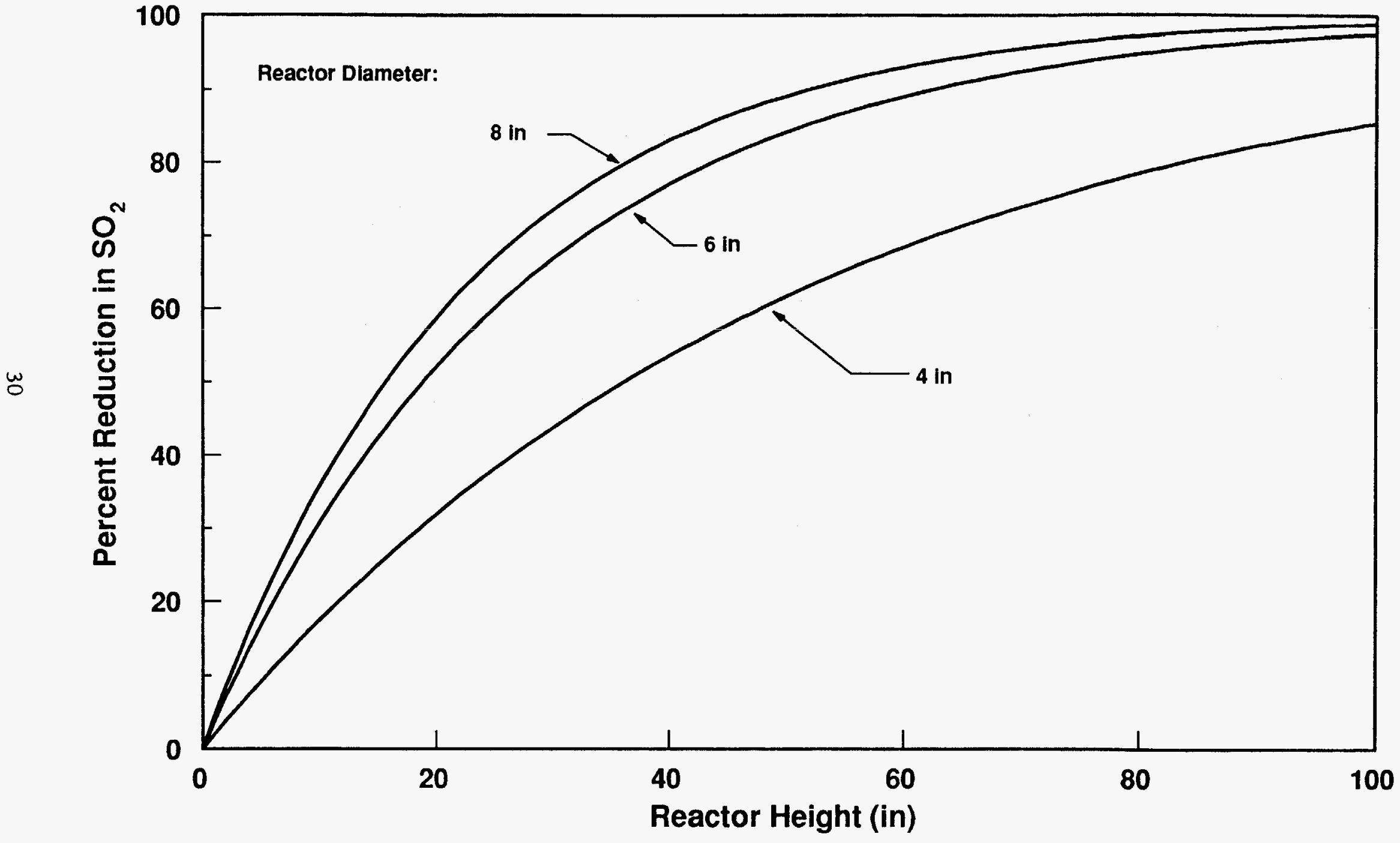

Figure 3.6 Effect of Reactor Height on Reactor Performance 


\section{e. Effect of Input Rate}

The effect of increasing the flow rate through the reactor at equivalent input rates ranging from 100,000 to $400.000 \mathrm{Btu} / \mathrm{hr}$ on reactor performance is shown in Figure 3.7. For this case, the reactor height was chosen to be $50 \mathrm{in}$., the $\mathrm{Ca} / \mathrm{S}$ ratio was 3:1, and only a reactor diameter of $8 \mathrm{in}$. was considered. The reason for considering only the 8-in. diameter reactor was that as the flow rate increased for the 4- and 6-in. reactors, pressure drop became considerable.

As input rate is increased, reactor performance decreases in a linear fashion from 88.9 percent at $100,000 \mathrm{Btu} / \mathrm{hr}$ to 58.5 percent for an input rate of $400,000 \mathrm{Btu} / \mathrm{hr}$. The linear decrease in performance (as opposed to an inverse decrease in performance with increasing flow rate) is due to the ability of the reactor to separate smaller particles at higher tangential velocities. As the input rate increases, the gas residence time decreases as the inverse of the input rate. Therefore, since the higher inlet velocities allow the reactor to be operated with a smaller size optimal particle diameter at the higher input rates, there is essentially more relative surface area within the reactor to participate in $\mathrm{SO}_{2}$ capture. For this reason there is not as much of a dramatic decrease in performance as flow rate is increased. The effect of input rate on optimal particle diameter for an 8-in. diameter reactor is shown in Figure 3.8.

\subsection{TASK 3.2 - PROTOTYPE COMPONENT DESIGN}

In an effort to simplify $\mathrm{NO}_{\mathrm{x}}$ and $\mathrm{SO}_{2}$ emissions reduction work, two separate initial prototype component test facilities were designed. The purpose of having two separate test facilities was to have as high a degree of flexibility as possible for testing the individual components. For example, while one component in a particular test facility is being modified, testing can continue in the other test facility with no loss of continuity.

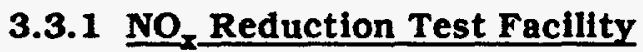

The first test facility was designed for $\mathrm{NO}_{\mathbf{x}}$ reduction work. A schematic diagram of this test facility is shown in Figure 3.9. This test facility consists of the CWS combustor, transition box, heat exchanger, baghouse, and various support equipment and instrumentation. At the heart of the $\mathrm{NO}_{\mathrm{x}}$ reduction test facility is the CWS combustor, where $\mathrm{NO}_{\mathrm{x}}$ emissions are controlled by operating the unit under staged conditions.

The CWS combustor used in this work is a derivative of the one that was developed by Tecogen Inc. under contract No. DE-AC22-87PC79650. A cutaway 
Predicted $\mathrm{SO}_{2}$ Reduction Reactor Performance

Inlet Concentration: 3,000 ppm (Ca/S = 3:1)

Reactor Height: 50 in Reactor Diameter: 8 in.

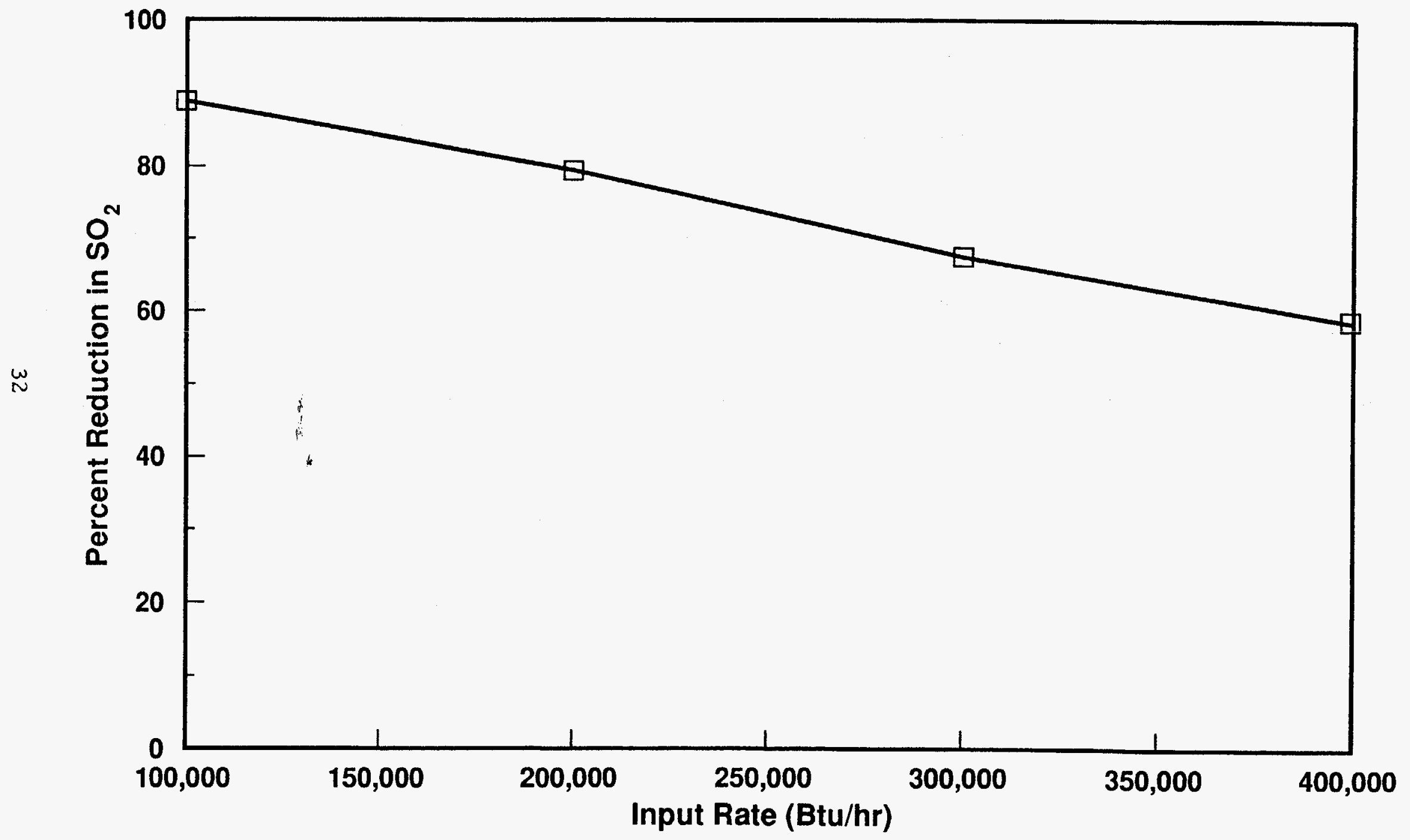

Figure 3.7 Effect of Input Rate on Reactor Performance 
Optimal Particle Diameter as a Function of Input

Reactor Height: 50 in.

Inlet Conc.: 3,000 ppm (Ca/S = 3:1)

$\stackrel{\omega}{\omega}$

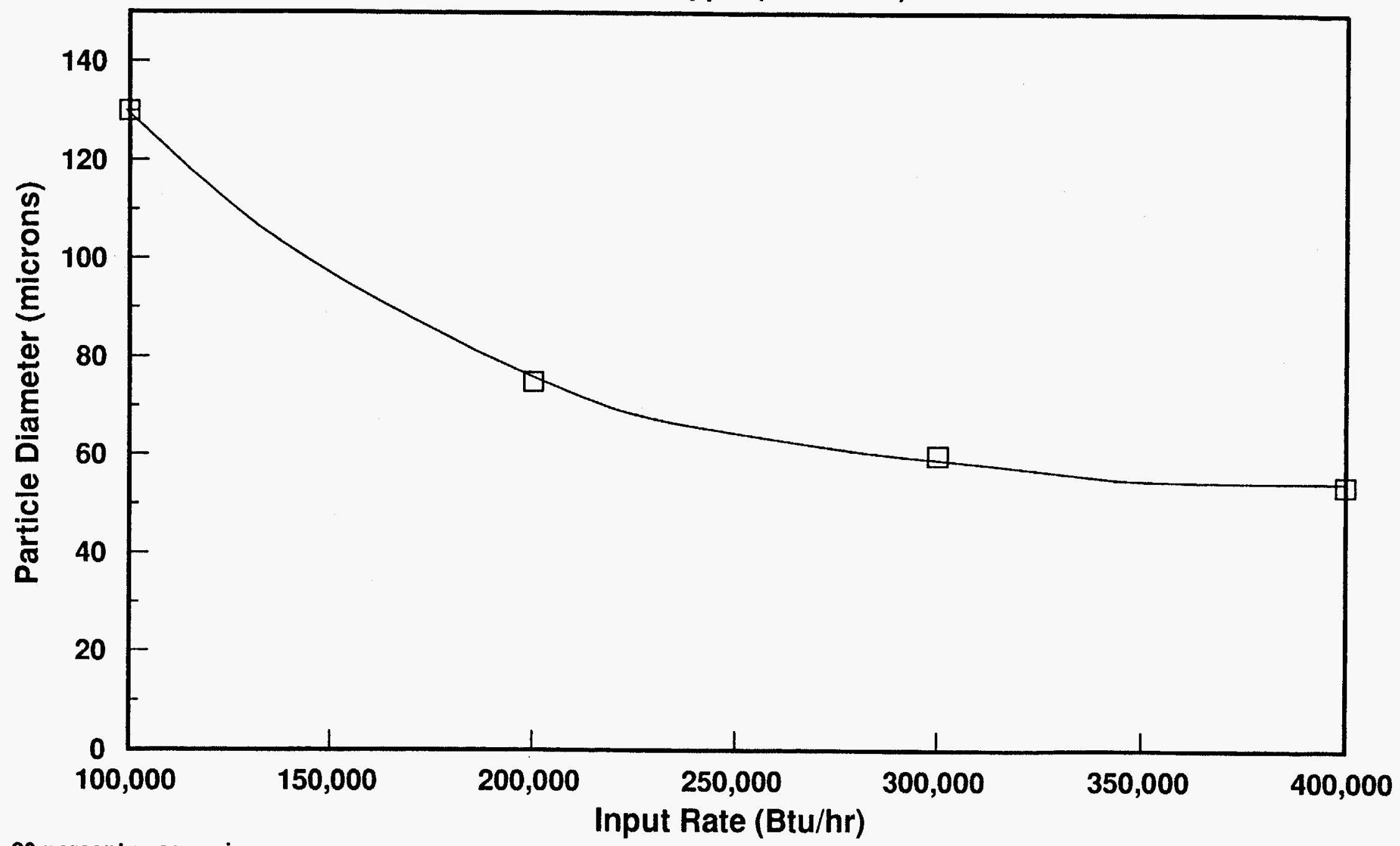

20 percent excess air

Figure 3.8 Effect of Input Rate on Optimal Particle Diameter 
O
1
$\infty$
$\frac{1}{1}$
1

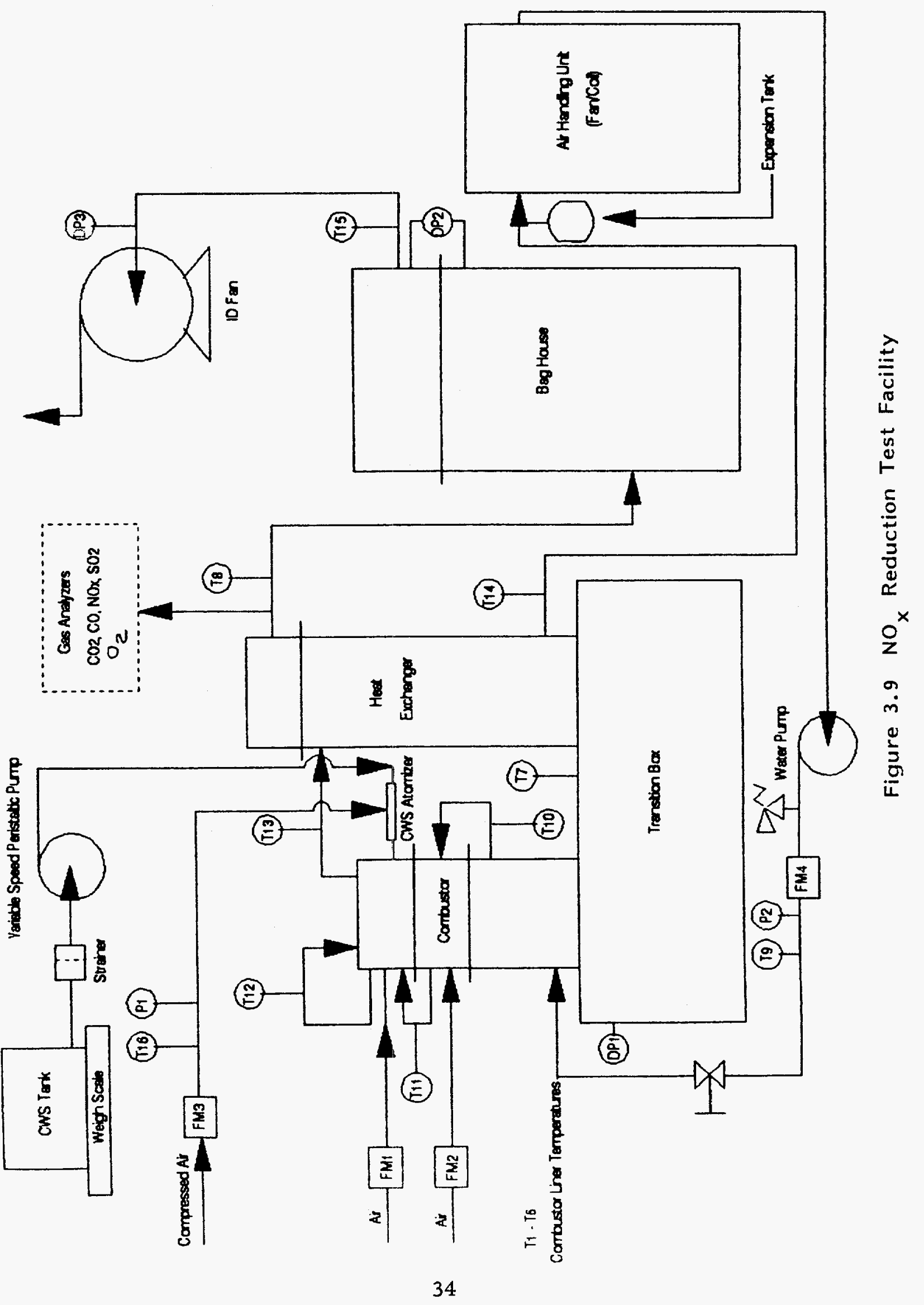


drawing of the combustor is shown in Figure 3.10. The combustor makes use of centrifugal forces, set up by a predominantly tangential flow field, to separate and confine larger unburned particles in the upper chamber. Various partitions are used to retard the downward, axial flow of these particles and thus maximize the residence time of these particles in the hottest section of the furnace.

As the particles burn and their size decreases, radial drag forces overcome the centrifugal forces, and the particles are able to exit the primary chamber. Combustion of these smaller particles is completed in a secondary chamber. Control of $\mathrm{NO}_{x}$ emissions in this combustor is accomplished by staging the combustion air between upper and lower sections of the primary combustion chamber, such that the unit operates in a substoichiometric manner in the upper section of the primary combustion chamber. The combustor was designed such that different inserts could be used to change the height of the upper primary chamber, and thereby change the residence time of the products of combustion in this fuel-rich zone.

The atomizer used in this work is similar in design to the supersonic CWS combustor previously developed at Tecogen Inc. This atomizer was annular in design, with CWS flowing in the central tube while atomizing air flowed in the annular passageway around the CWS tube. The airstream shears the CWS to an unstable ligament sheet which breaks up into droplets external to the atomizer. To aid in the atomization process, the airstream was accelerated to supersonic velocities by means of a converging/diverging section. A photograph of the atomizer operating with oil is shown in Figure 3.11. In order to accurately determine the primary/stoichiometric ratio in the upper primary chamber of the combustor, the atomizing airnow rate and the combustion inlet airflow rate were measured accurately.

\subsection{2 $\mathrm{SO}_{2}$ Reduction Test Facility}

A schematic diagram of the $\mathrm{SO}_{2}$ reduction test facility is shown in Figure 3.12. In order to have more control over the operation of the $\mathrm{SO}_{2}$ reactor, it was decided to operate the facility with flue gases produced from an oil burner and inject $\mathrm{SO}_{2}$ as required in order to obtain desired inlet concentrations. Also, since oil burners can operate over a very wide range of input rates, typically from 68,500 to over $400,000 \mathrm{Btu} / \mathrm{hr}$ for residential scale burners, they provide a great deal of flexibility in reactor operation.

The $\mathrm{SO}_{2}$ reduction reactor was designed on the principle of axial recirculation. In a vortical now field, the pressure at the periphery is greater than that at the centerline. This is shown in Figure 3.13 where normalized curves of pressure difference as a function of radial position are presented. By connecting 


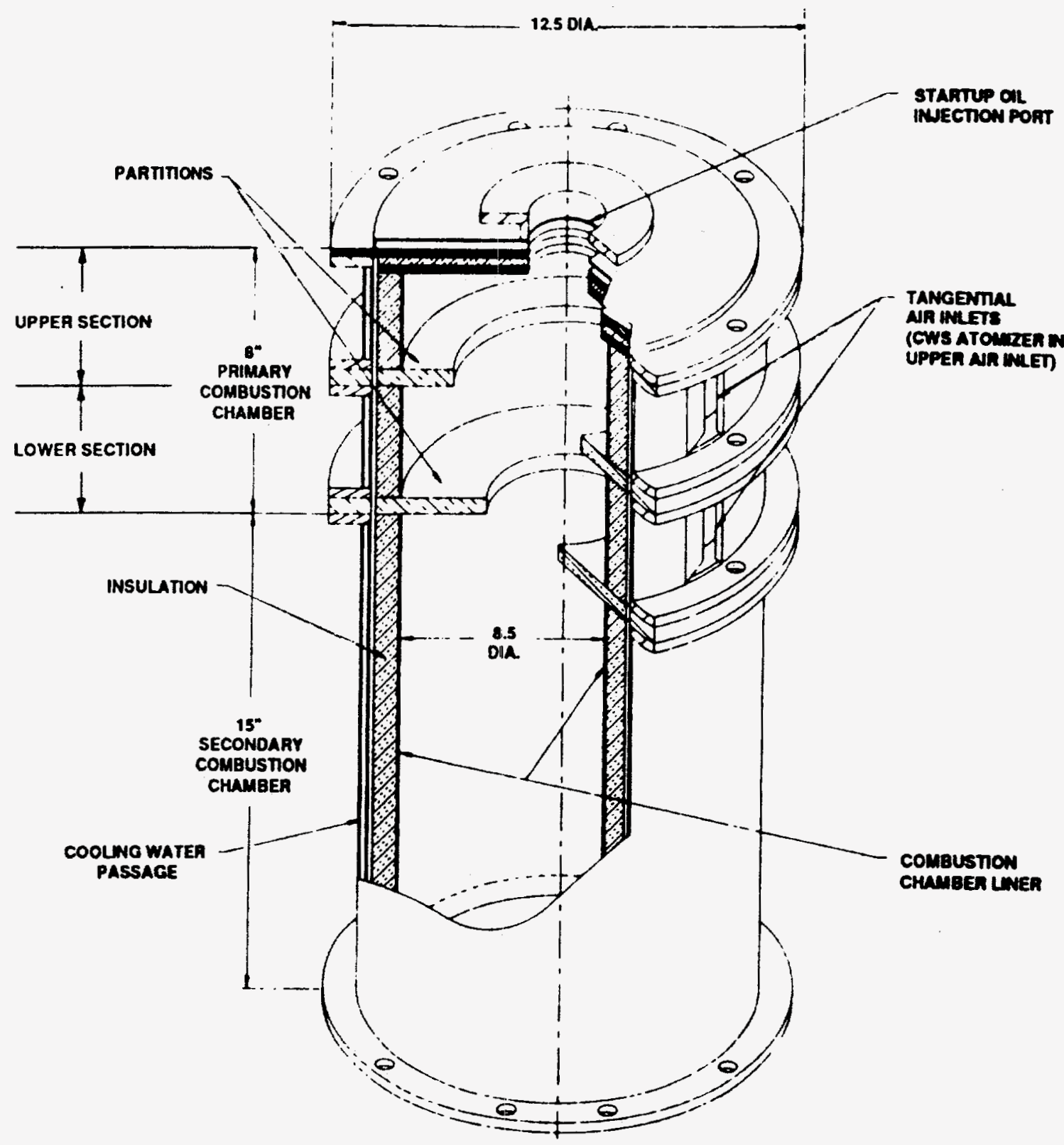

Figure 3.10 Cutaway Drawing of CWS-Fired Residential Combustor 
TF54-290

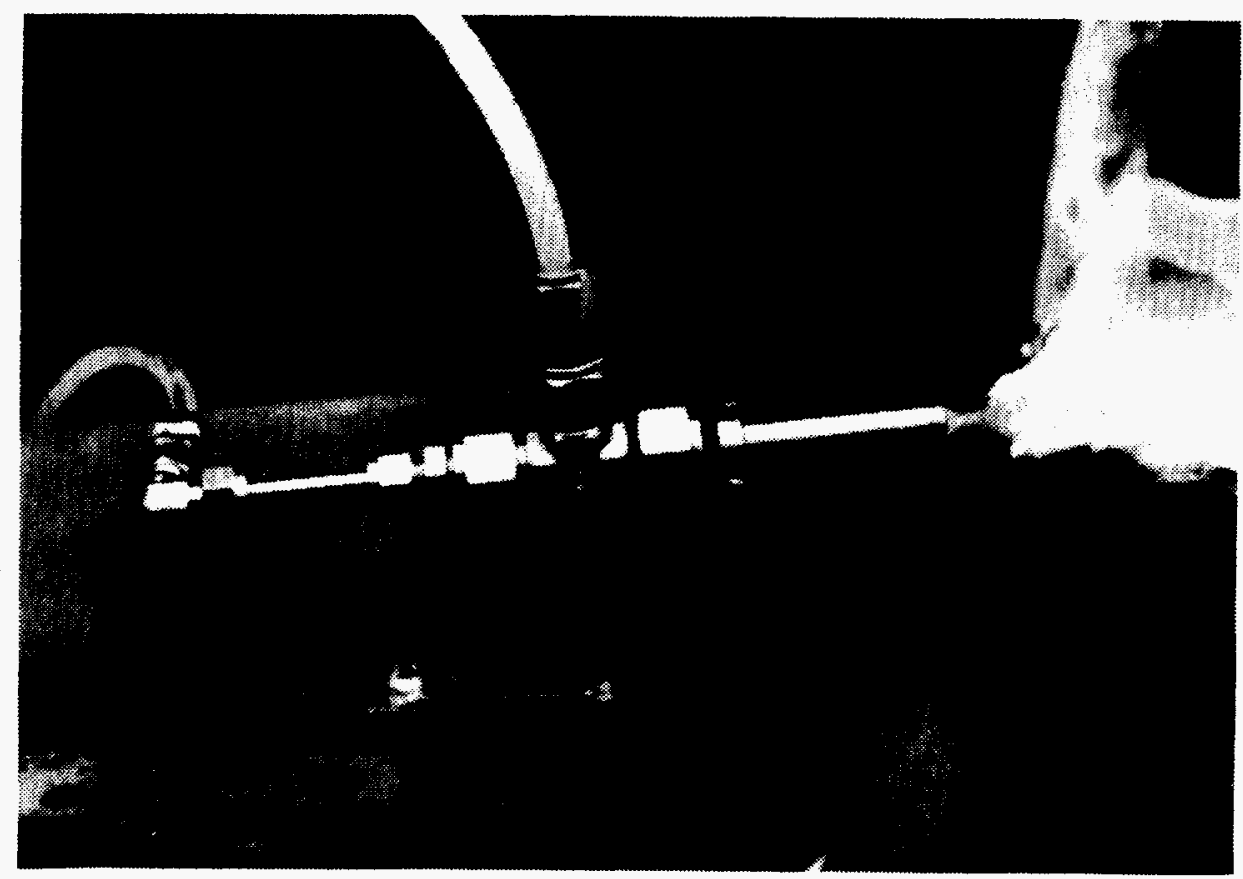

Figure 3.11 Atomizer Operating with Oil 


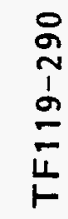
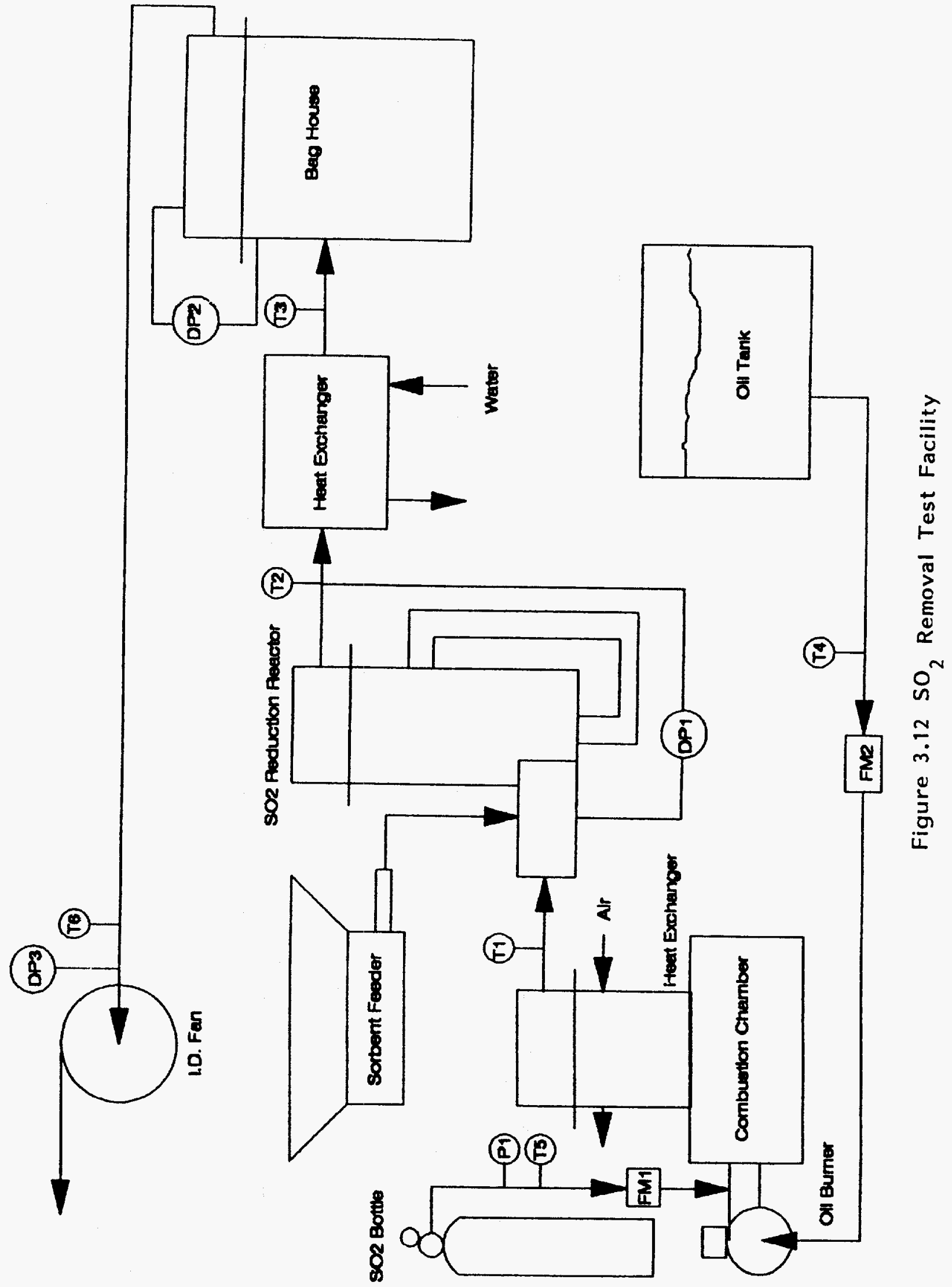


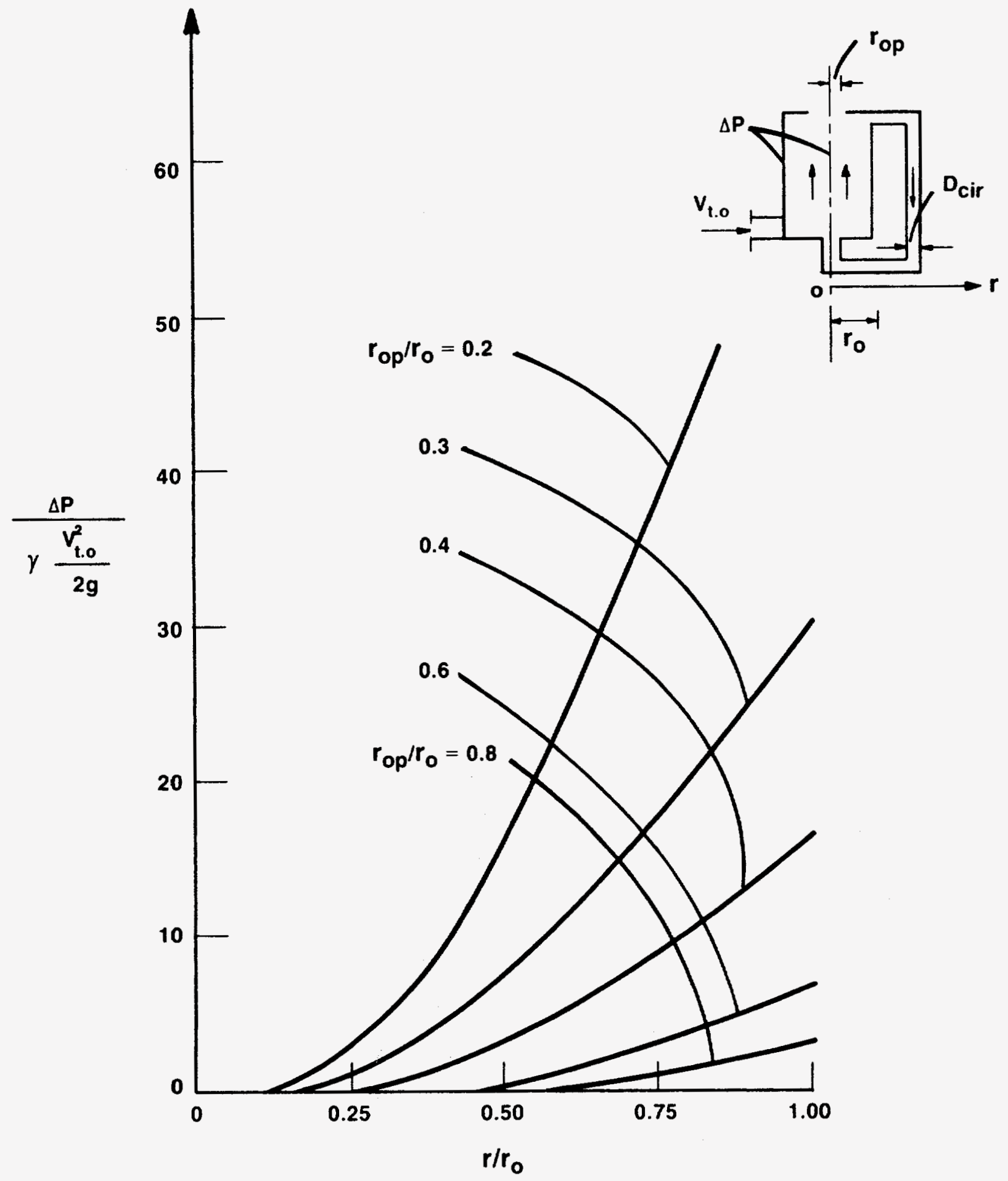

Figure 3.13 Normalized Static Pressure Distributions Inside Axial Recirculation Emissions Control Reactor 
one end of a tube tangentially from the periphery at one axial location, and the other end at the centeriine, an external axial recirculation flow path is established that operates only on the natural pressure difference present in the vortical flow field without the need of external assistance.

When the principle of axial recirculation is used in a gas/solids system, the residence time of the solids within the reactor can be significantly increased relative to that of the gas. A schematic diagram of both the internal and external particle recirculation paths is shown in Figure 3.14, whlle a photograph of the external particle recirculation is shown in Figure 3.15.

For the initial prototype reactor components, it was decided to fabricate the reactor from standard stainless-steel pipe in order to facilitate modifications. Two separate reactors were designed, one 6 inches in diameter, the other 8 inches in diameter. Both reactors were designed to be modular so that various length spool pieced could either be added or removed in order to vary the gas residence time.

\subsection{TASK 4.1 - INITIAL PROTOTYPE COMPONENT FABRICATION AND ASSEMBLY}

During the first year of this program, component fabrication and assembly of both the $\mathrm{NO}_{\mathrm{x}}$ and $\mathrm{SO}_{2}$ test facilities were completed. A photograph of the $\mathrm{NO}_{\mathrm{x}}$ test facility is shown in Figure 3.16, and a photograph of the $\mathrm{SO}_{2}$ reduction test facility is shown in Figure 3.17. In order to construct both test facilities in a costeffective manner, it was decided to allow both facilities to share certain components. These included the baghouse and the cooling water/dump radiator loop.

\subsection{TASK 5 - INITIAL PROTOTYPE COMPONENT TESTING}

During the first year of this program, lesting began on both the $\mathrm{NO}_{\mathrm{x}}$ and $\mathrm{SO}_{2}$ reduction test facilities.

\subsubsection{NO $\underline{\text { Reduction Testing }}$}

The CWS combustor was tested under both unstaged and staged conditions. Under both operating conditions, the combustor geometry, specifically the upper primary chamber, was modified to determine the effect of residence time on $\mathrm{NO}_{x}$ emissions. The CWS used during this testing contained 65.16-percent coal by weight, with the parent coal having a mean particle diameter of 14.0 microns. All the propertles of the CWS are summarized in Table 3.4. 


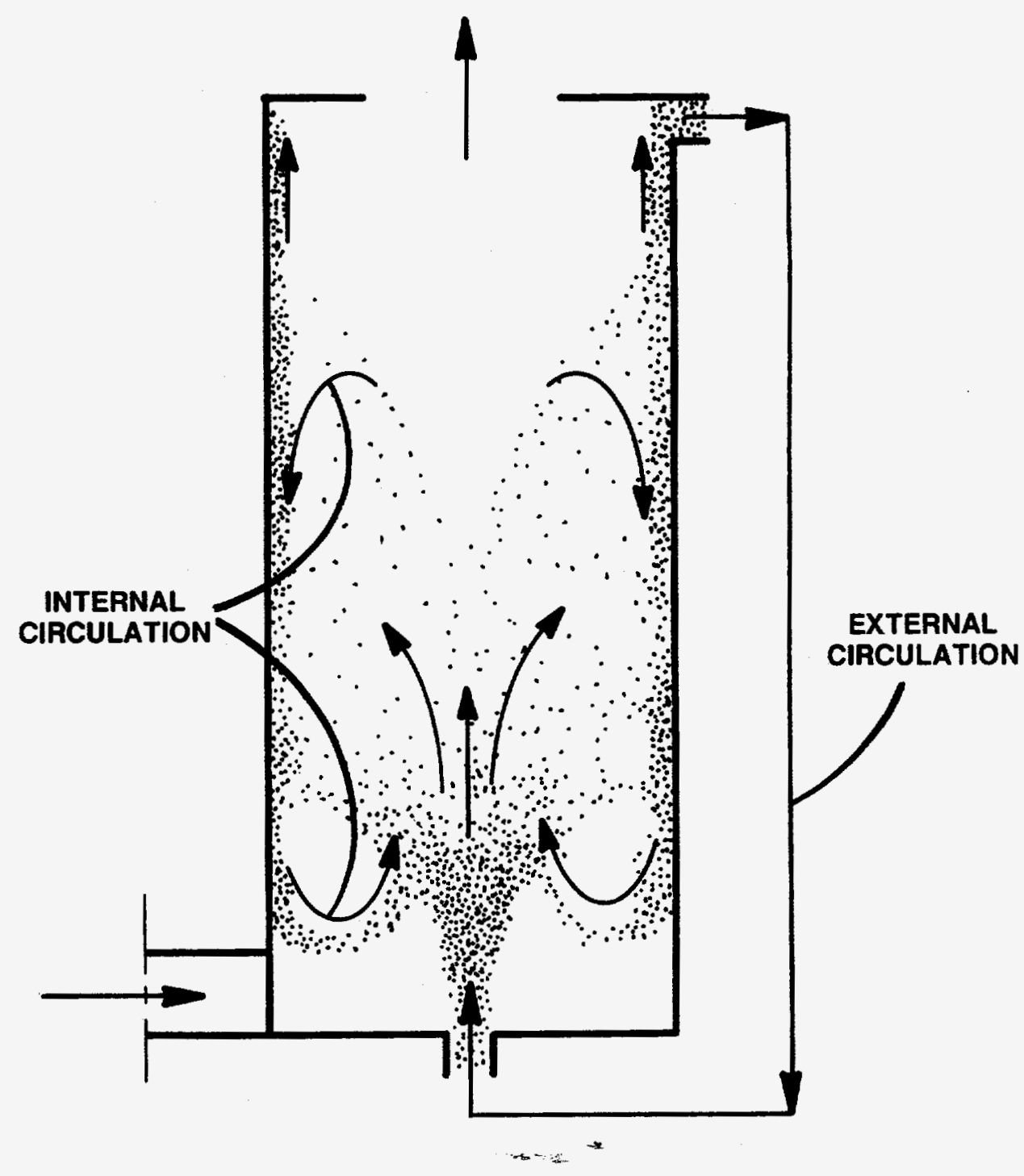

Figure 3.14 External and Internal Circulation in the Emissions Control Reactor 
1227-N

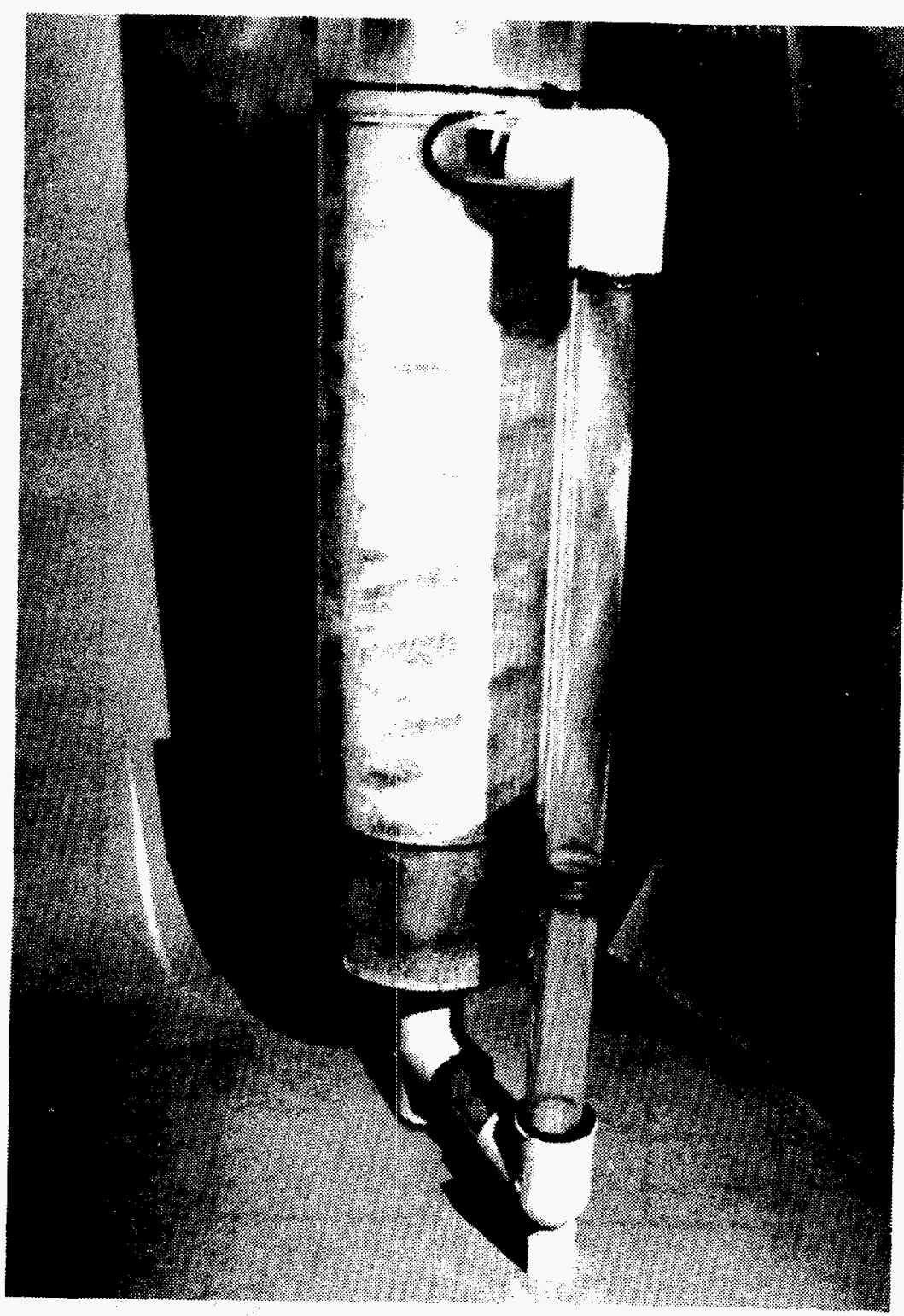




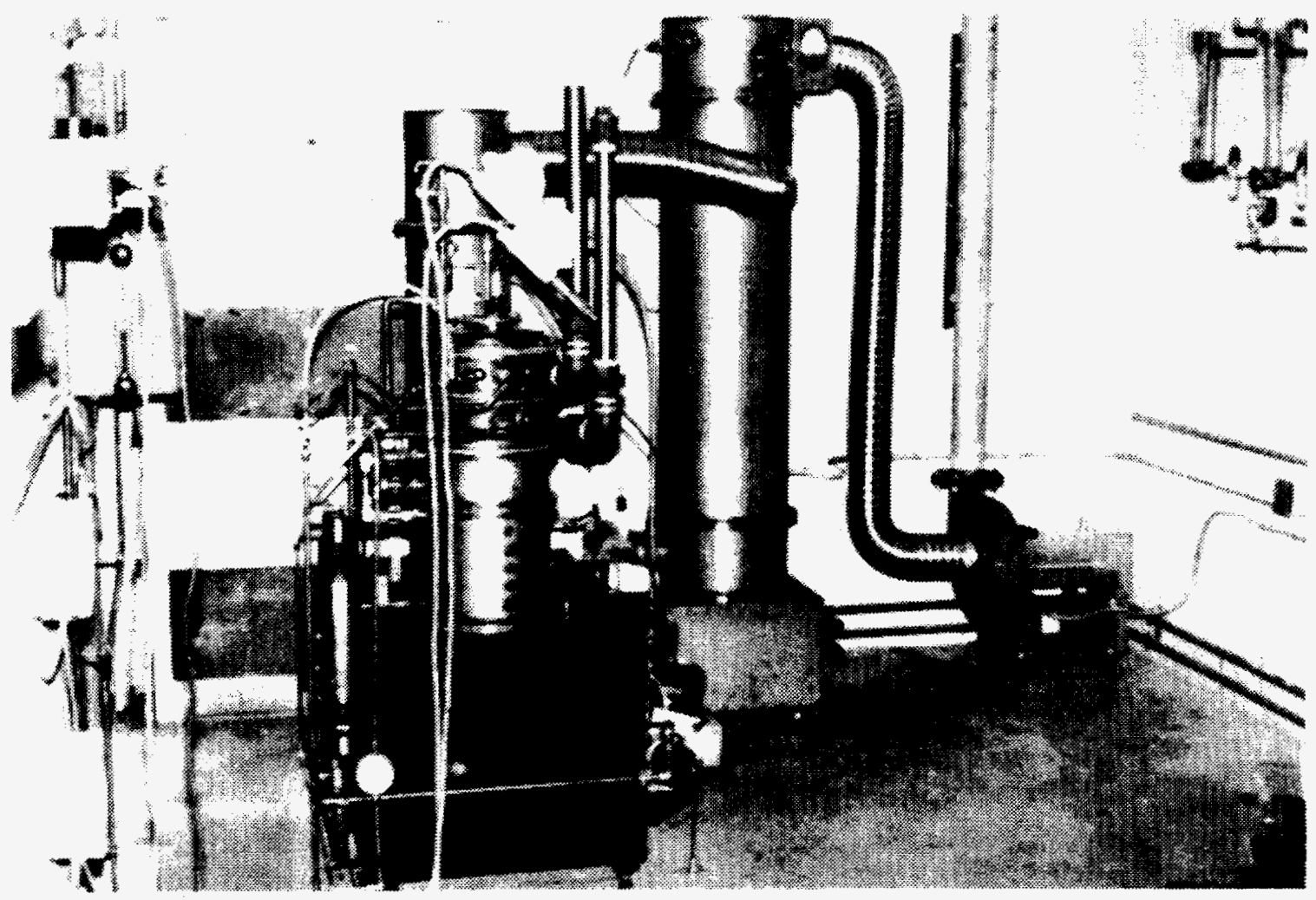

Figure 3.16 Photograph of $\mathrm{NO}_{x}$ Test Facility 
TF23-990

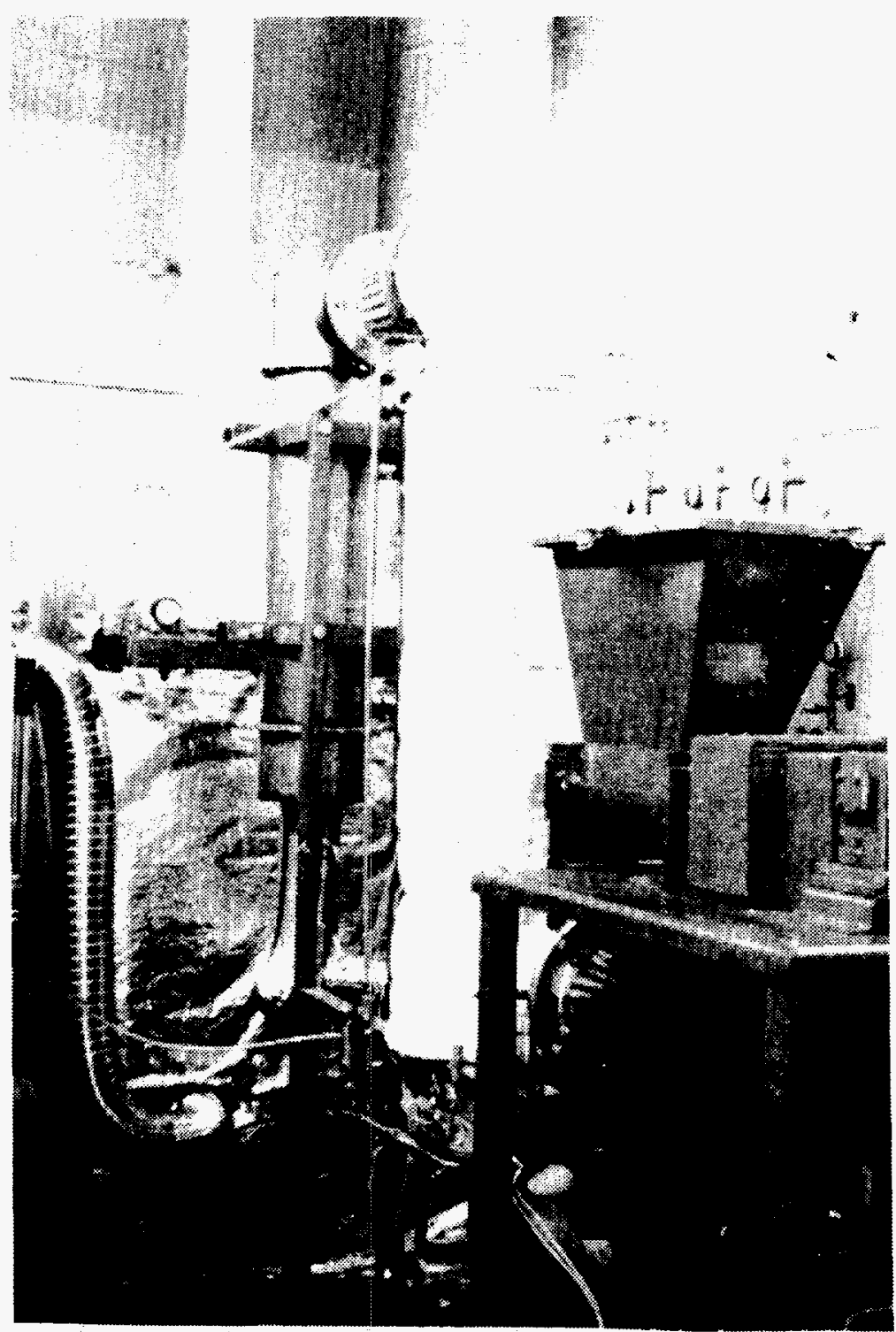

Figure $3.17 \mathrm{SO}_{2}$ Test Facility 
TABLE 3.4

FUEL PROPERTIES

\begin{tabular}{|l|l|}
\hline Identification & Upper Elkhorn Number 3 Seam \\
\hline Heating Value & 15,251 Btu/lbm \\
\hline Ash & 1.32 percent (by weight) \\
\hline Sulfur & 0.66 percent (by weight) \\
\hline $\begin{array}{l}\text { Ash Fuslon Temperatures } \\
\text { Initial }\end{array}$ & $2150^{\circ} \mathrm{F}$ \\
Softening & $2300^{\circ} \mathrm{F}$ \\
Fluid & $2400^{\circ} \mathrm{F}$ \\
T-250 & $2509^{\circ} \mathrm{F}$ \\
\hline Ultimate Analysis & \\
Carbon & 85.40 percent \\
Hydrogen & 5.40 percent \\
Nitrogen & 1.59 percent \\
\hline Solids Content & $65.16 \%$ \\
\hline Mean Particle Size & $14 \mu \mathrm{m}$ \\
\hline Viscosity at $100 \mathrm{~s}-1$ & $419 \mathrm{cps}$ \\
\hline
\end{tabular}




\section{a. Unstaged Operation}

As part of unstaged testing, $\mathrm{NO}_{\mathbf{x}}$ emissions were recorded under various input rates ranging from 113,400 to $181,700 \mathrm{Btu} / \mathrm{hr}$, and for two different primary combustion chamber heights of 3 and 7.69 inches (see Figure 3.10). For these tests, the combustor tangential air inlet height equalled the entire length of the primary chamber. These results are shown in Figure 3.18 as a function of stoichiometric ratio. Preliminary results for unstaged operation have shown $\mathrm{NO}_{\mathrm{x}}$ emissions to be fairly insensitive to input rate and primary chamber residence time. Peak $\mathrm{NO}_{\mathrm{x}}$ emissions are on the order of 0.78 pound of $\mathrm{NO}_{\mathrm{x}}$ per million Btu fired and occurred at just under 40-percent excess air. Operation of the combustor at stoichiometric conditions produced $\mathrm{NO}_{\mathrm{x}}$ emissions on the order of 0.285 pound per million Btu fired.

Though primary chamber residence time has little effect on the total amount of $\mathrm{NO}_{\mathbf{x}}$ produced during unstaged operation, it was found to have an effect on the amount of $\mathrm{NO}_{x}$ produced in the form of $\mathrm{NO}_{2}$. This is shown in Figure 3.19 where the percent of $\mathrm{NO}_{x}$ in the form of $\mathrm{NO}_{2}$ on a weight basis is plotted as a function of stoichiometric ratio. At lower stoichiometric ratios, the amount of $\mathrm{NO}_{2}$ produced is low for both chamber heights that were tested: however, as the stoichiometric ratio is increased, the longer chamber (which provides a longer gas residence time) has a higher percentage of total $\mathrm{NO}_{x}$ in the form of $\mathrm{NO}_{2}$.

The fact that $\mathrm{NO}_{2}$ is present in the products of combustion of CWS is quite unexpected when thermochemical equilibrium is considered. As an indication of the amount of $\mathrm{NO}_{x}$ thermochemical equilibrium predicts for the combustion of CWS, Figure 3.20 shows the effect of both temperature and stoichiometric ratio on $\mathrm{NO}_{\mathbf{x}}$ production, primarily in the form of NO. Equilibrium analysis predicts that $\mathrm{NO}_{2}$ is present only in insignificant quantities, i.e., mole fractions of less than $10^{-5}$. The fact that $\mathrm{NO}_{2}$ is present in the products of combustion when equilibrium does not favor its formation is an interesting phenomenon.

One possible explanation for this occurrence is the presence of $\mathrm{HO}_{2}$ radicals in the flame region. It has been suggested that in the flame region NO molecules are scavenged by $\mathrm{HO}_{2}$ radicals to form $\mathrm{NO}_{2}$ and $\mathrm{OH}$. Due to the water present in the CWS, it is expected that there is a higher probabllity of $\mathrm{HO}_{2}$ radicals being present, which would contribute to the formation of $\mathrm{NO}_{2}$.

Another reason for the presence of $\mathrm{NO}_{2}$ in the products of combustion can be attributed to the presence of sodium. Sodium has been shown to aid in the formation of $\mathrm{NO}_{2}$, and since it is quite possible to have sodium present in the water used in the preparation of the CWS, it may help account for the presence of $\mathrm{NO}_{2}$. 


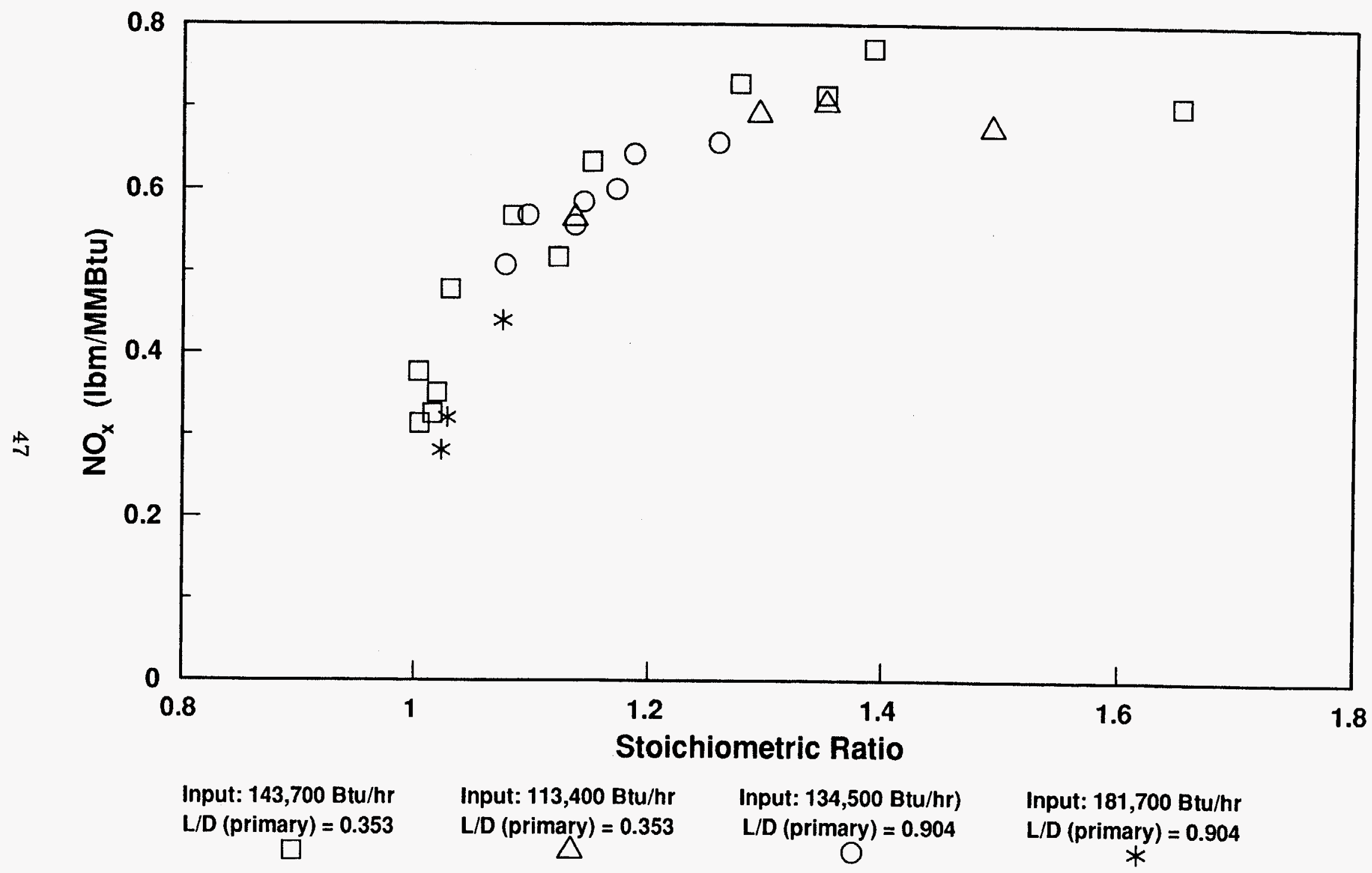

Figure 3.18 NO $_{x}$ as a Function of Stoichiometric Ratio for Unstaged Operation 
TF29-790

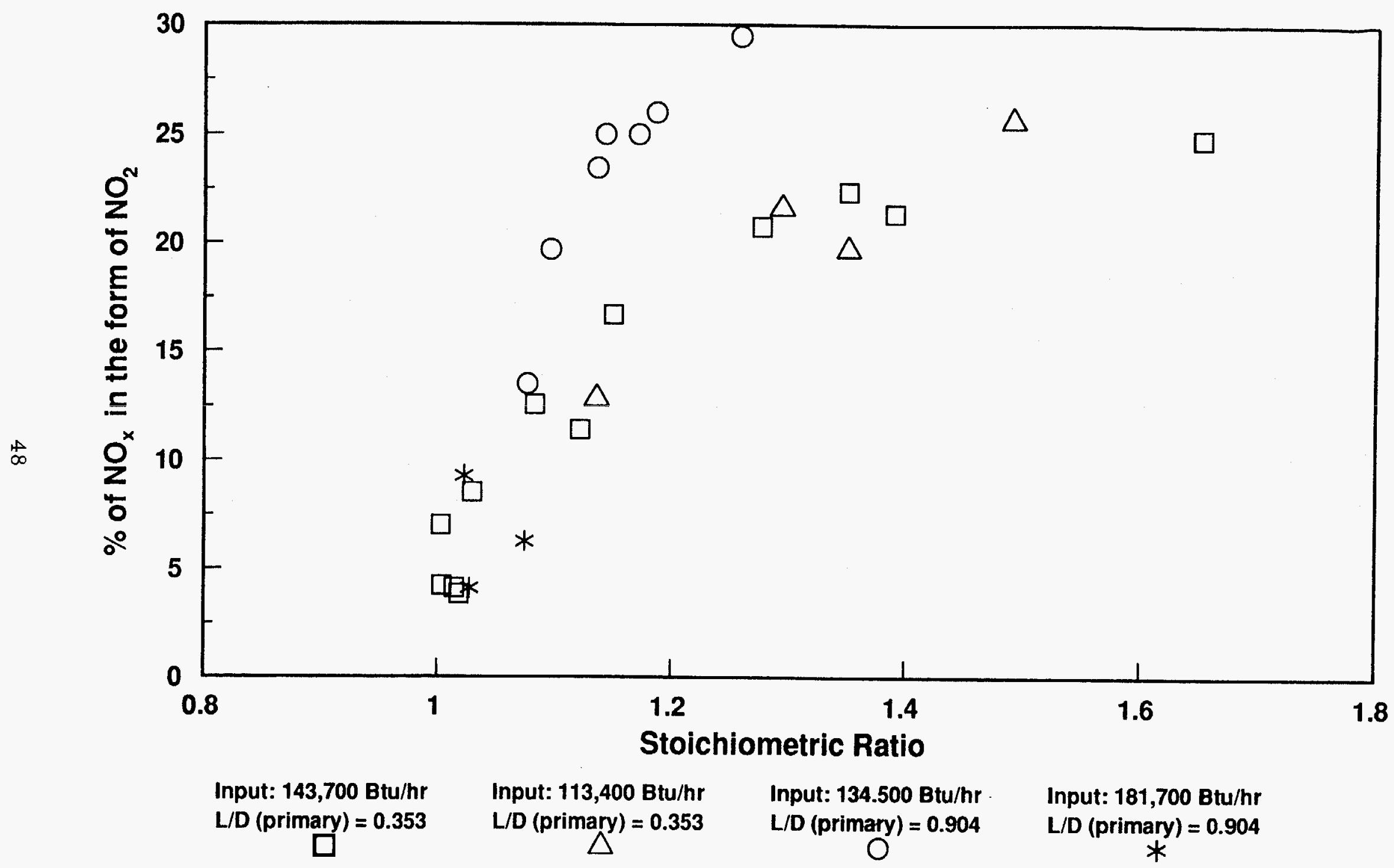

Figure 3.19 Weight Percent of Total $\mathrm{NO}_{x}$ in the Form of $\mathrm{NO}_{2}$ as a Function of Stoichiometric Ratio 
TF30-790

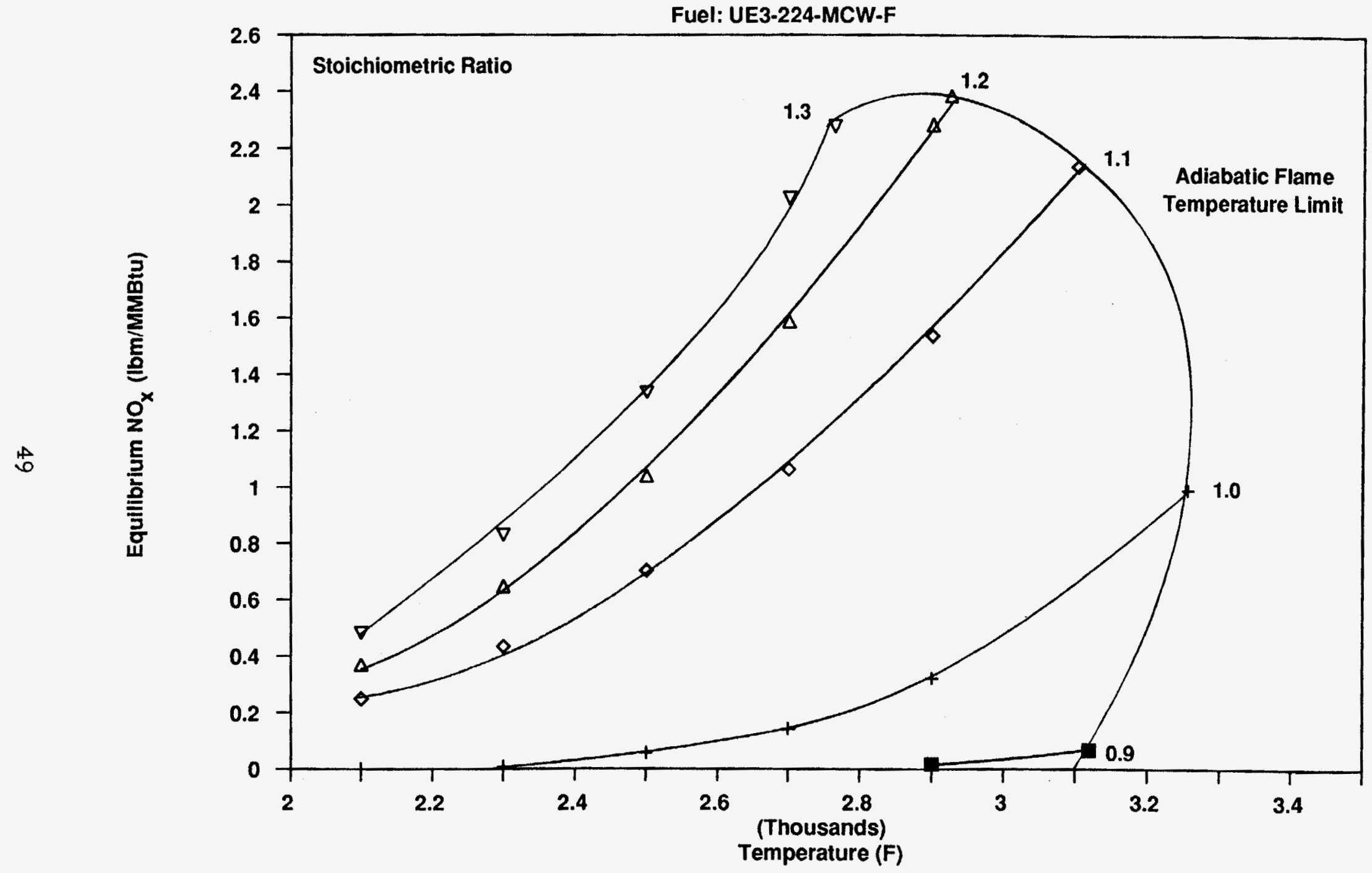

Figure 3.20 Thermochemical Equilibrium $\mathrm{NO}_{x}$ Concentration as a Function of Temperature and Stoichiometric Ratio for the Combustion of Coal Water Slurry 


\section{b. Staged Operation}

Under staged operating conditions, the CWS combustor was tested under two different configurations, shown schematically in Figure 3.21. The geometry of the first configuration, denoted Configuration 1, was the following. The combustor had a diameter of $8.5 \mathrm{in.}$. and the height of the upper primary chamber was $7.69 \mathrm{in}$. The air inlet to this chamber extended the entire length of the upper primary chamber, and this atr, along with that from the CWS atomizer, established the primary/stoichiometric ratio under which the combustor operated. The upper primary chamber was separated from the lower primary chamber by a partition that had an 5.75-in. diameter opening. The secondary air inlet was situated in the lower primary chamber, which was 3.5 in. high. Below the lower primary chamber was the secondary chamber, which was 15 in. high and was separated from the lower primary chamber by a 4-in.-diameter partition.

Combustor Configuration 1 was limited to a minimum primary/stoichiometric air ratio of about 0.6 , since at lower airflow rates the tangential velocity in the upper primary chamber was not sufficient to prevent particle agglomeration on the wall. In order to reduce staging even further, the combustor was reconfigured in the following manner, which was denoted Configuration 2. The upper primary chamber was modified such that the upper partition was now $2.5 \mathrm{in}$. below the combustor head, with the primary air inlet extending the entire $2.5 \mathrm{in}$. length. Below the upper partition was a spacer section that was $9 \mathrm{in}$. high. This spacer section separated the upper primary section from the lower primary section and provided additional residence time for the products of combustion in the fuel-rich primary zone as compared to Configuration 1 . The height of the lower primary chamber was reduced from $3.5 \mathrm{in}$. in Configuration 1 to 3 in. in Configuration 2. Beyond these changes, all other geometric relations were kept the same.

Testing of the CWS combustor in Configuration 2 ylelded lower $\mathrm{NO}_{\mathrm{x}}$ levels than were obtained in Configuration 1. A comparison of the two configurations as a function of primary/stolchiometric ratio is shown in Figure 3.22. In comparing data from Configurations 1 and 2 over the range of primary/stolchiometric ratios tested, Configuration 2 had consistently lower $\mathrm{NO}_{x}$ levels even for identical primary/stoichiometric air ratios. Also, since Configuration 2 was capable of operating at higher primary chamber tangential velocities, it could be operated at lower primary/stoichiometric ratios without agglomerations problems and achieve $\mathrm{NO}_{\mathrm{x}}$ levels as low as 0.285 pound of $\mathrm{NO}_{\mathrm{x}}$ per million Btu fired.

In comparing combustor Configurations 1 and 2, the main difference is the length of the upper primary chamber, which provides Conflguration 2 with a longer 

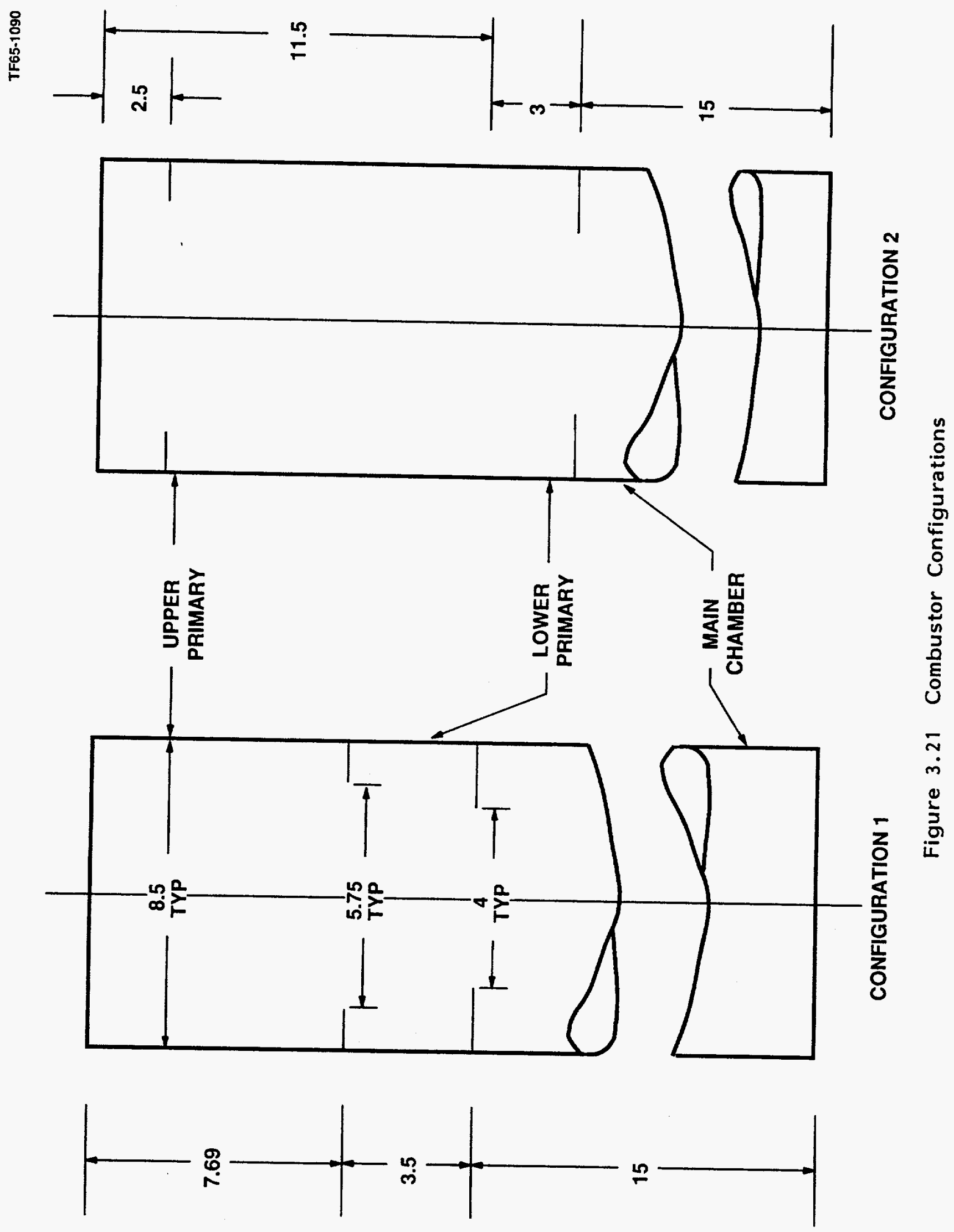
TF14-990r

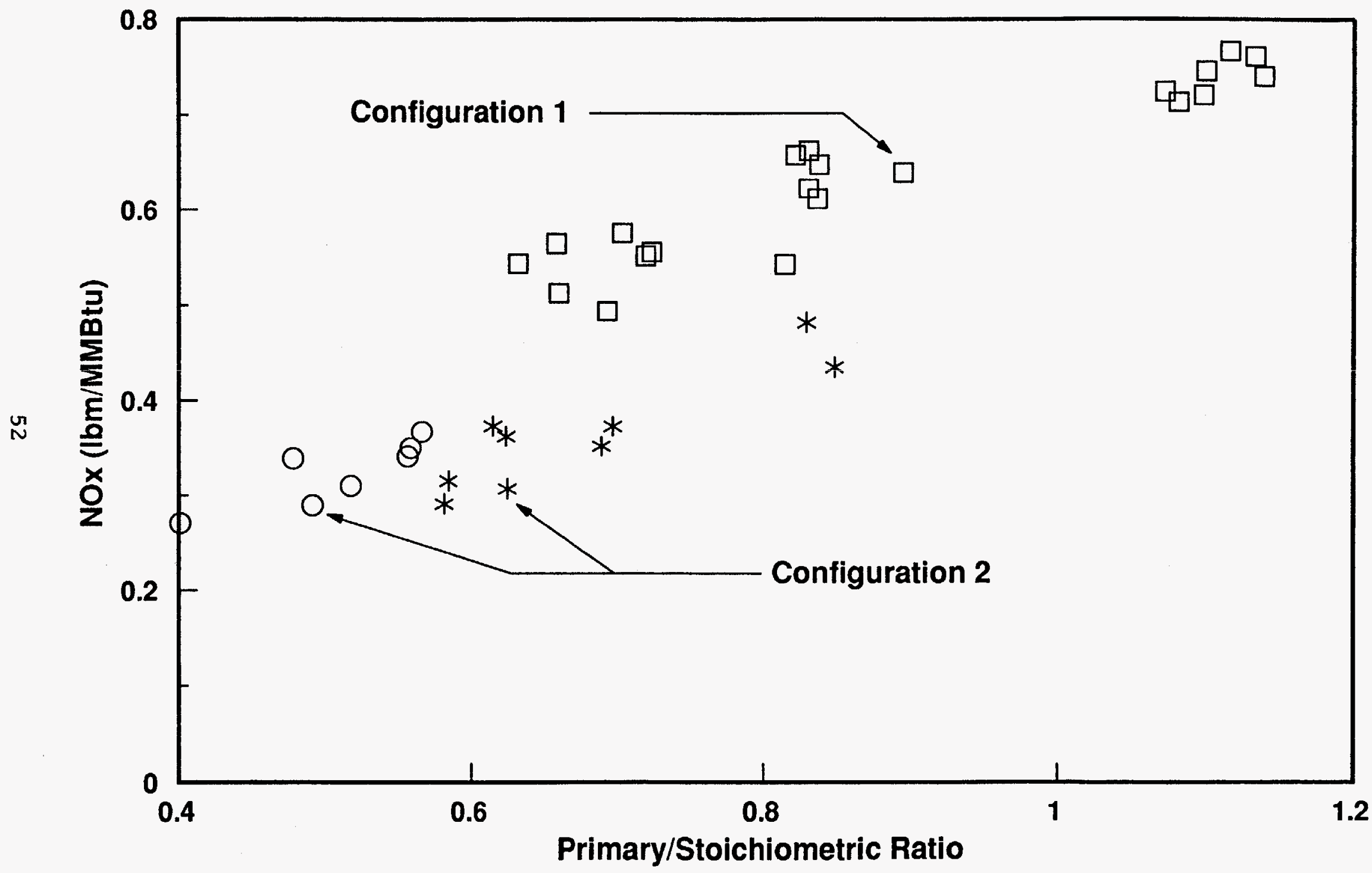

Figure 3.22 Comparison Between Combustor Configurations Configurations 1 and 2 
residence time in the fuel-rich zone of the combustor. When $\mathrm{NO}_{x}$ data for Configurations 1 and 2 are plotted as a function of residence time in the primary chamber, it can be seen that the difference between the two configurations diminishes, and residence time becomes the key parameter affecting $\mathrm{NO}_{\mathrm{x}}$ emissions over the data range tested to date. These results are shown in Figure 3.23.

As in the case of unstaged operation. $\mathrm{NO}_{2}$ was found in the products of combustion even though thermochemical equilibrium predicts $\mathrm{NO}_{2}$ should be present only in insignificant quantities. Figure 3.24 shows $\mathrm{NO}_{2}$ emissions as a function of primary/stoichiometric ratio for combustor Configurations 1 and 2 . Referring to Figure 3.24, $\mathrm{NO}_{2}$ emissions appear to be a fairly linear function of primary/stoichiometric ratio, increasing as more air is avallable in the primary zone.

\subsection{2 $\mathrm{SO}_{2}$ Reduction Testing}

$\mathrm{SO}_{2}$ reduction testing began in the last quarter of the first year of this program, and to date has been of a preliminary nature. These tests have been conducted on the 6-in.-nominal diameter which has the following geometry:

$\begin{array}{lr}\text { Inside Diameter: } & 6.065 \text { in. } \\ \text { Recirculation Line Diameter: } & 1.049 \text { in. } \\ \text { Active Reactor Height: } & 45 \mathrm{in} .\end{array}$

The sorbent used in this testing was a standard dolomite variety of lime used for residential lawn applications. This sorbent was approximately 60 -percent calcium carbonate, $\mathrm{CaCO}_{3}$, and for identification purposes it was denoted Limestone 1. The particle size distribution of this limestone was determined by a sieve analysis, which yielded a mass mean particle diameter of 194 microns. Results of the particle size analysis are shown in Figures 3.25 and 3.26.

The test procedure for the $\mathrm{SO}_{2}$ reduction reactor was as follows. First, the reactor was allowed to reach thermal steady state. At that point, a metered amount of $\mathrm{SO}_{2}$ was injected well upstream of the reactor. Upon reaching steady state, a metered amount of limestone was injected at the reactor inlet. Limestone feed would continue until after the reactor had reached steady-state conditions, after which the limestone feed was discontinued, ard $\mathrm{SO}_{2}$ emissions were monitored until after the reactor had again reached steady state conditions. The percent reduction in $\mathrm{SO}_{2}$ was then determined by using the average value of $\mathrm{SO}_{2}$ from before the limestone was injected, and well after injection had stopped. During testing, important data were recorded via a microcomputer-based data acquisition system. 
TF15-990

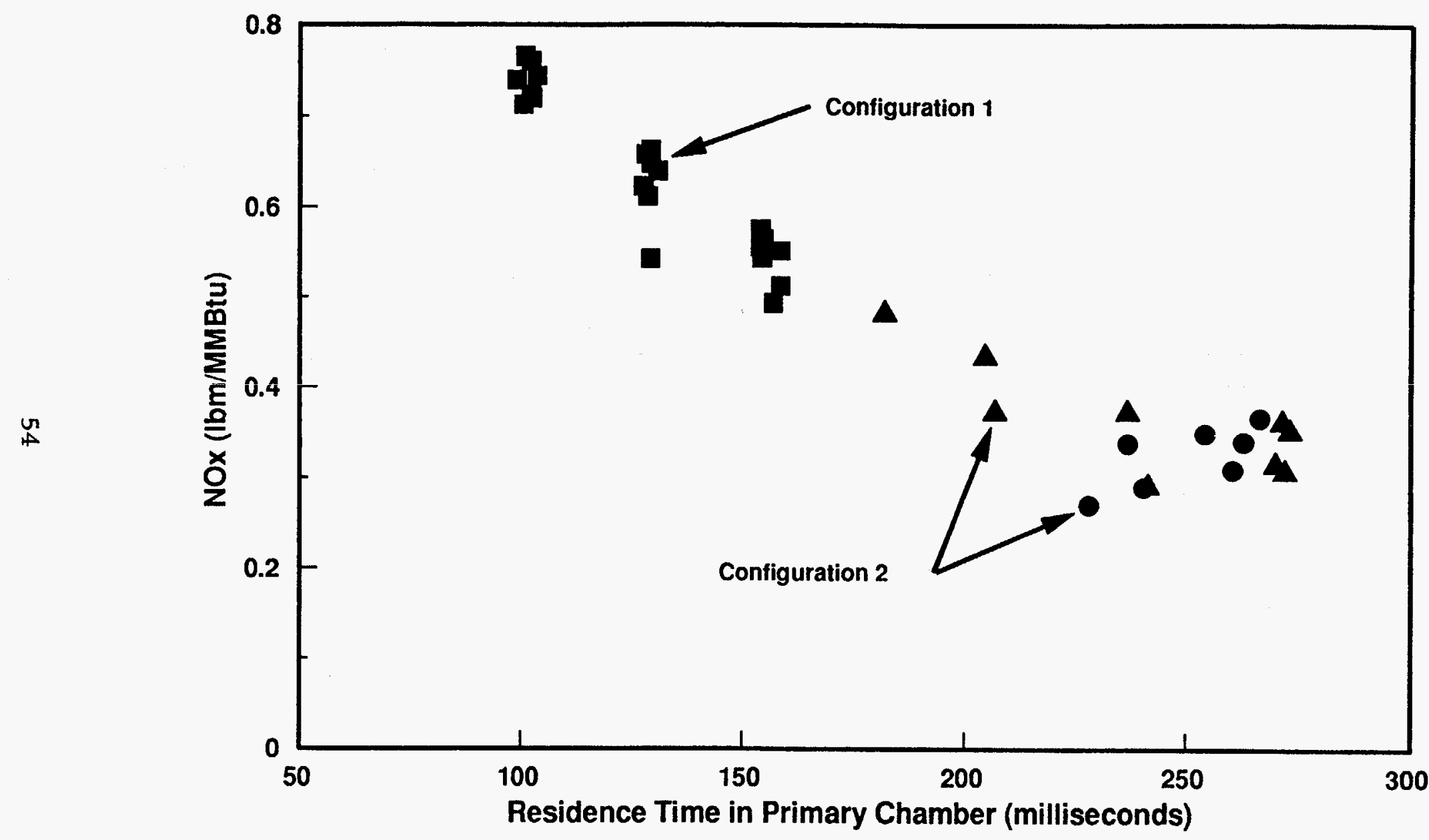

Figure 3.23 Comparison Between Combustor Configurations Configurations 1 and 2 


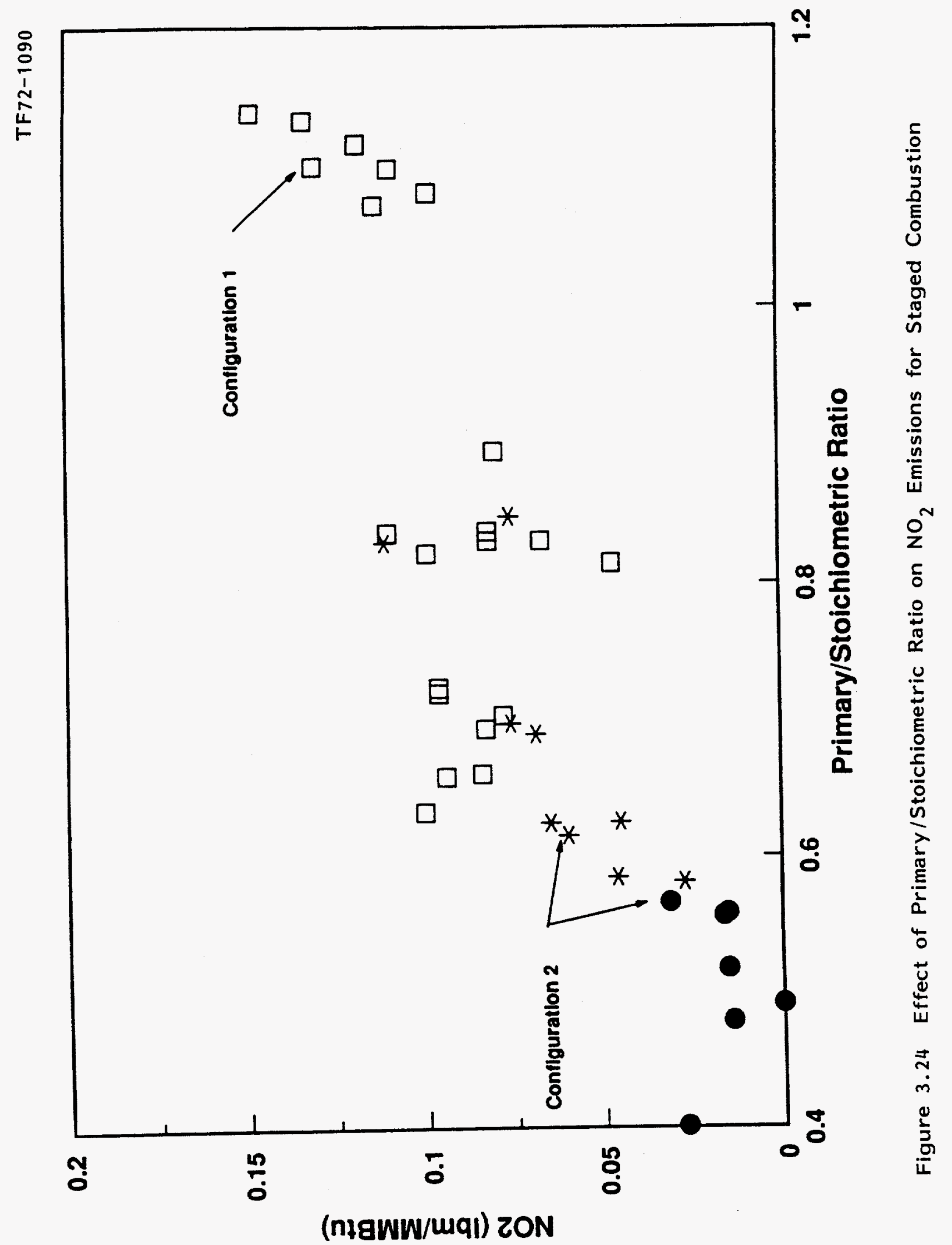




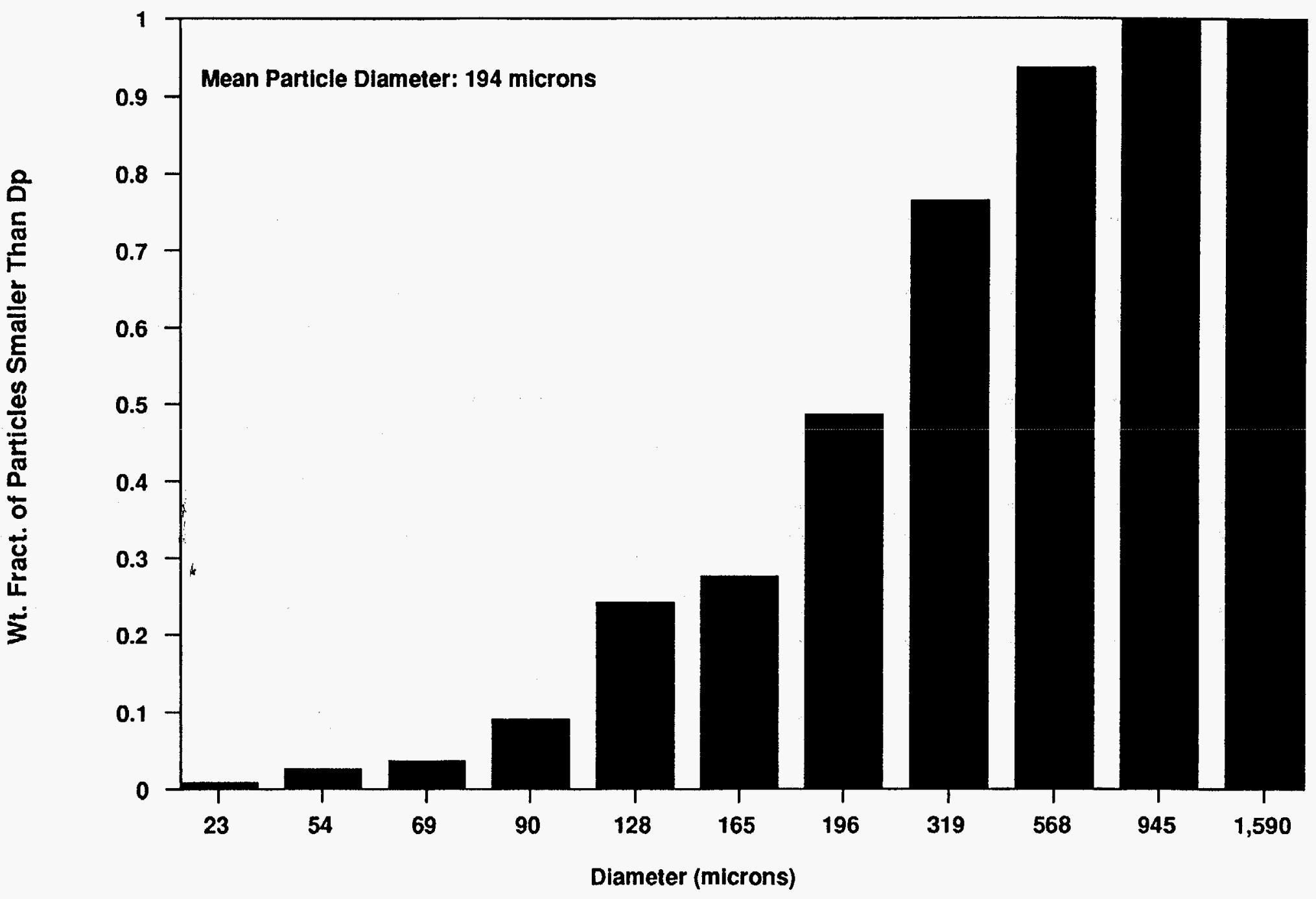

Figure 3.25 Particle Size Distribution for Limestone 1

(Weight Fraction of Particles Smaller

Than a Given Diameter) 


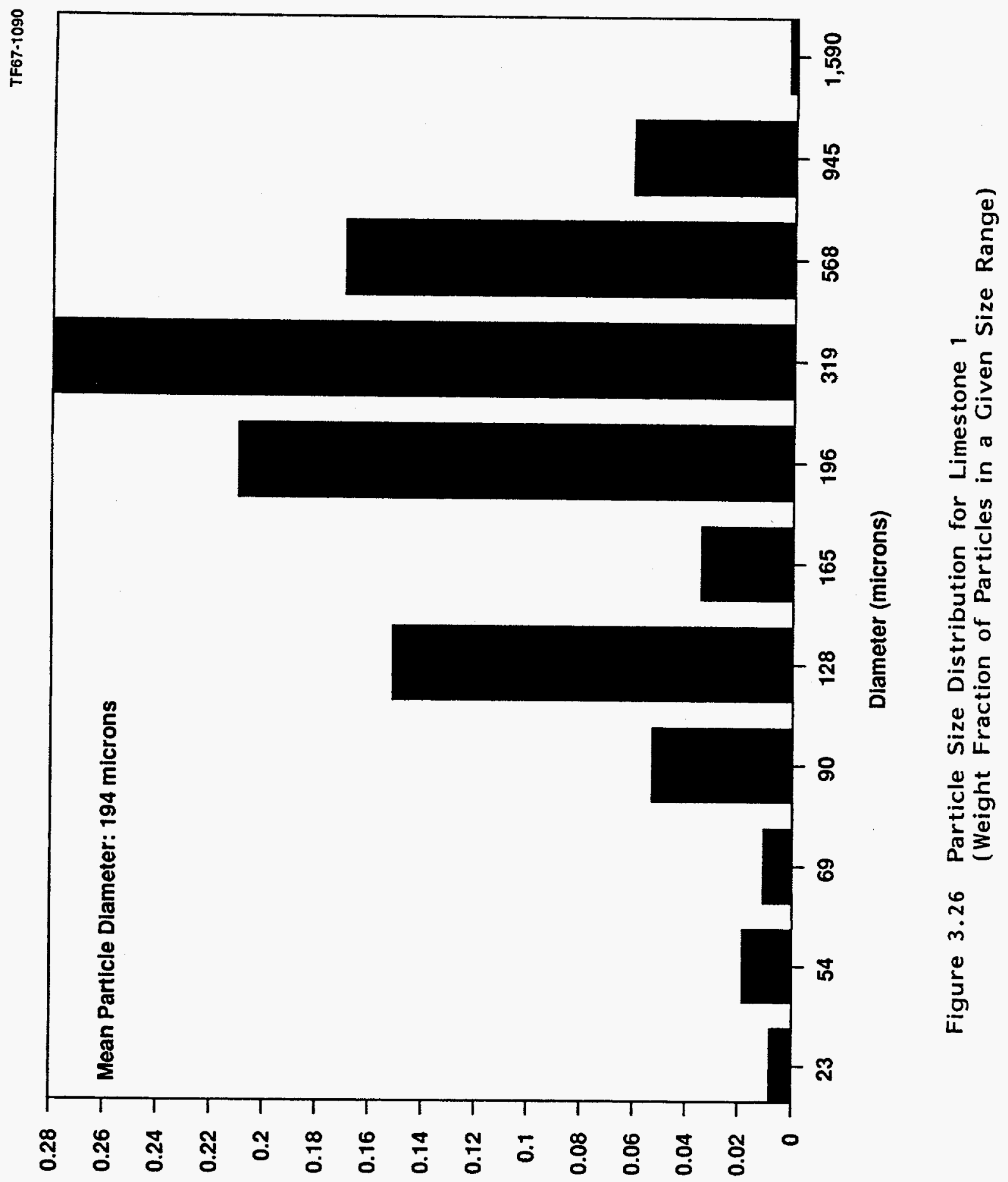

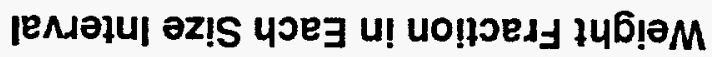


Results of a typical test are shown in Figure 3.27, in which $\mathrm{SO}_{2}$ emissions are plotted as a function of time for an inlet concentration of $2,075 \mathrm{ppm}$ of $\mathrm{SO}_{2}$. For this case, the reactor operated with an inlet mass flow rate of around $250 \mathrm{lbm} / \mathrm{hr}$. This is equivalent to a coal combustor operating with 25-percent excess air, at a firing rate of over $200.000 \mathrm{Btu} / \mathrm{hr}$. From Figure 3.27 , each reduction in $\mathrm{SO}_{2}$ refers to a specific $\mathrm{Ca} / \mathrm{S}$ ratio, which was varied from 1.7 to 5.3:1. For these operating conditions, the percent reduction in $\mathrm{SO}_{2}$ varied from 42 to 72.5 percent.

A plot of the percent reduction in $\mathrm{SO}_{2}$ as a function of the $\mathrm{Ca} / \mathrm{S}$ ratio is shown in Figure 3.28, where the data appears to exhibit an asymptotic behavior. The 72.5-percent reduction is quite good when the large diameter of the limestone is considered. In fact, while operating under these conditions, the reactor performed much better than what the model predicts. This is also shown in Figure 3.28, where the actual reduction in $\mathrm{SO}_{2}$ achieved is more than twice what the model predicts (solid line). For the model predictions, it was assumed that the limestone had an activation energy of $10.000 \mathrm{cal} / \mathrm{gmole}$ and a frequency factor of $335,0001 / \mathrm{sec}$. These values were representative of data presented for a dolomite in Borgwardi's paper. However, it should be noled that the kinetic constants for several stones tested by Borgwardt differed greatly and that the kinetic constants for our dolomite most likely differ considerably from Borgwardt's data.

Another possible explanation for the large difference in actual performance when compared with the model is due to the effect of the sorbent particle diameter. The model predictions shown in Figure 3.28 are based on the 194-micron particle diameter determined by sieve analysis (solid line). Within the reactor, high tangential velocities can lead to particle erosion, and thus the mean particle diameter within the reactor can be less than what is injected at the reactor inlet. If for example, within the reactor, the mean particle diameter is 40 microns, the model predicts the reaclor would achieve a 67 -percent reduction in $\mathrm{SO}_{2}$, which is fairly close to the actual reduction of 72.5 percent (dashed line).

\subsubsection{Particulate Control}

In order to meet the particulate emissions objective, a baghouse was used as a final particulate filter. The bag filters used in this system were made of Tellon and glass fibers needled into a woven scrim, known under the trade name of Tefaire. In order to facilitate filler cleaning, a pulse jet system was used. For this system, the bag filters were mounted on cages that are attached to a venturi. A photograph of the venturis and cages are shown in Figure 3.29. A pulse of compressed air, supplied from a delivery tube situated above the venturis induces a flow into the bags, which establishes a traveling wave that removes particulates from the filters. 


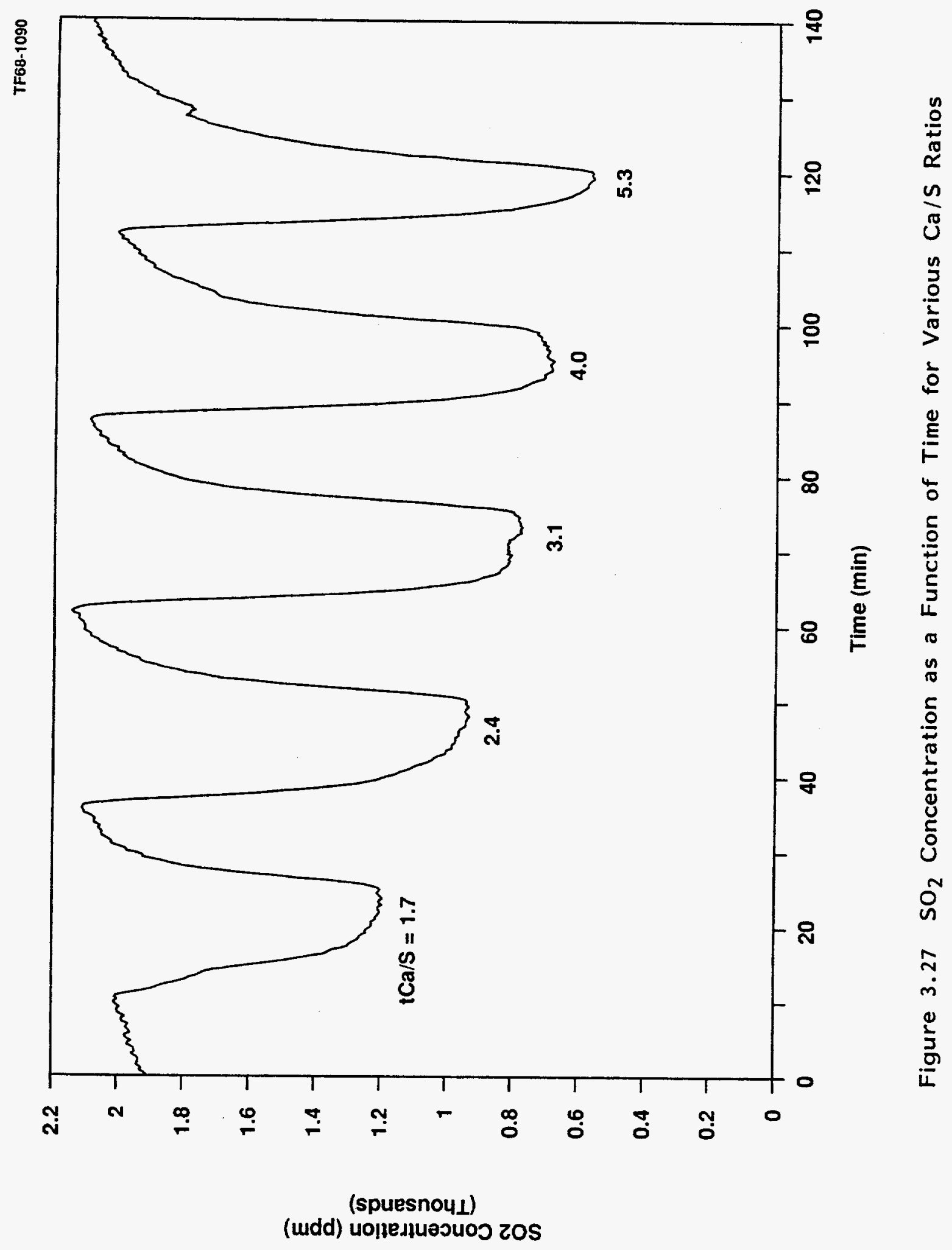


TF69-1090

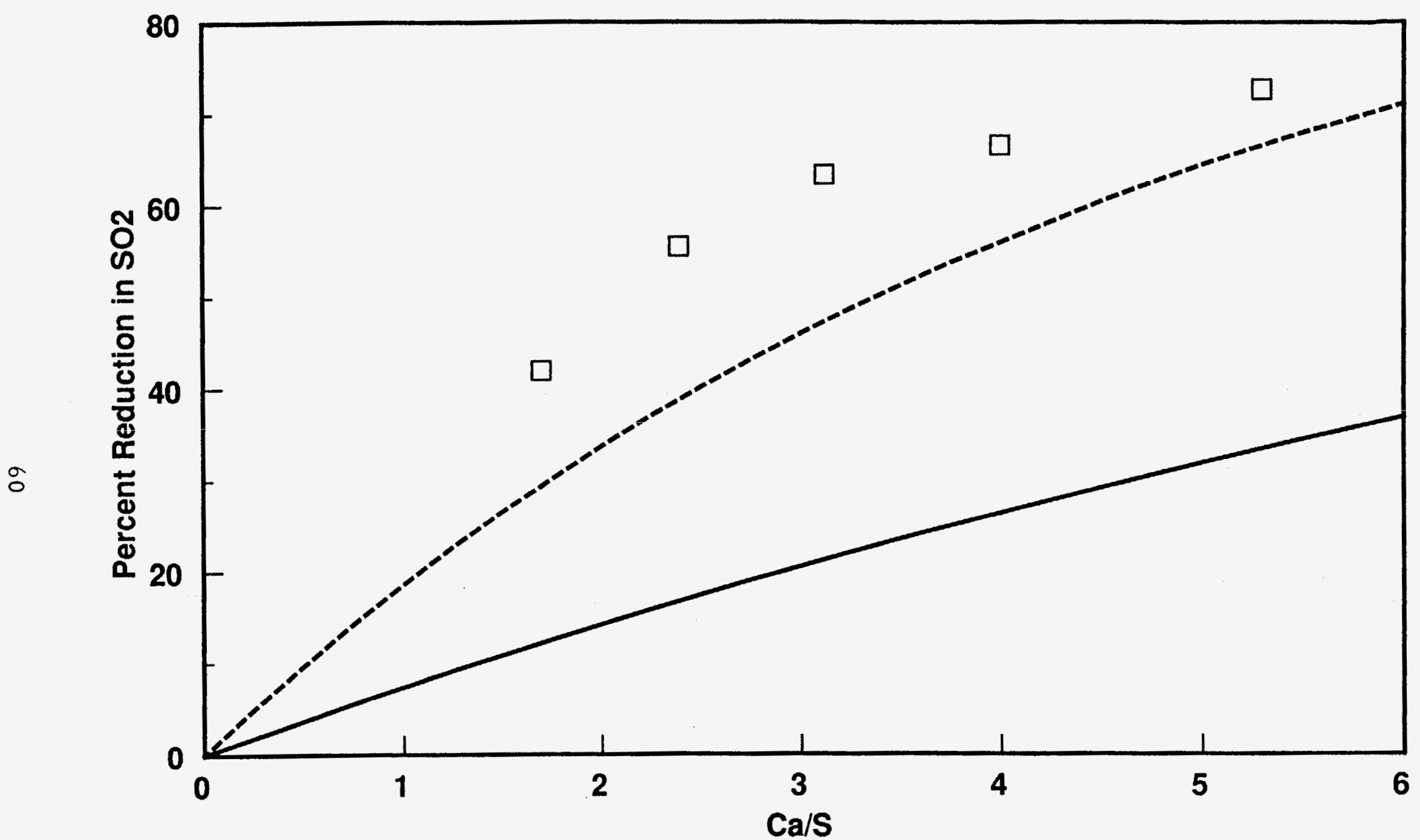

Data: 2,075 ppm Model: 2,075 ppm Model: 2,075 ppm

$D p=194$ microns $\quad D p=40$ microns

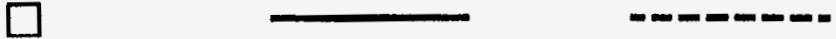

Figure 3.28 Effect of Ca/S Ratio on Reactor Performance 
TF81-1090

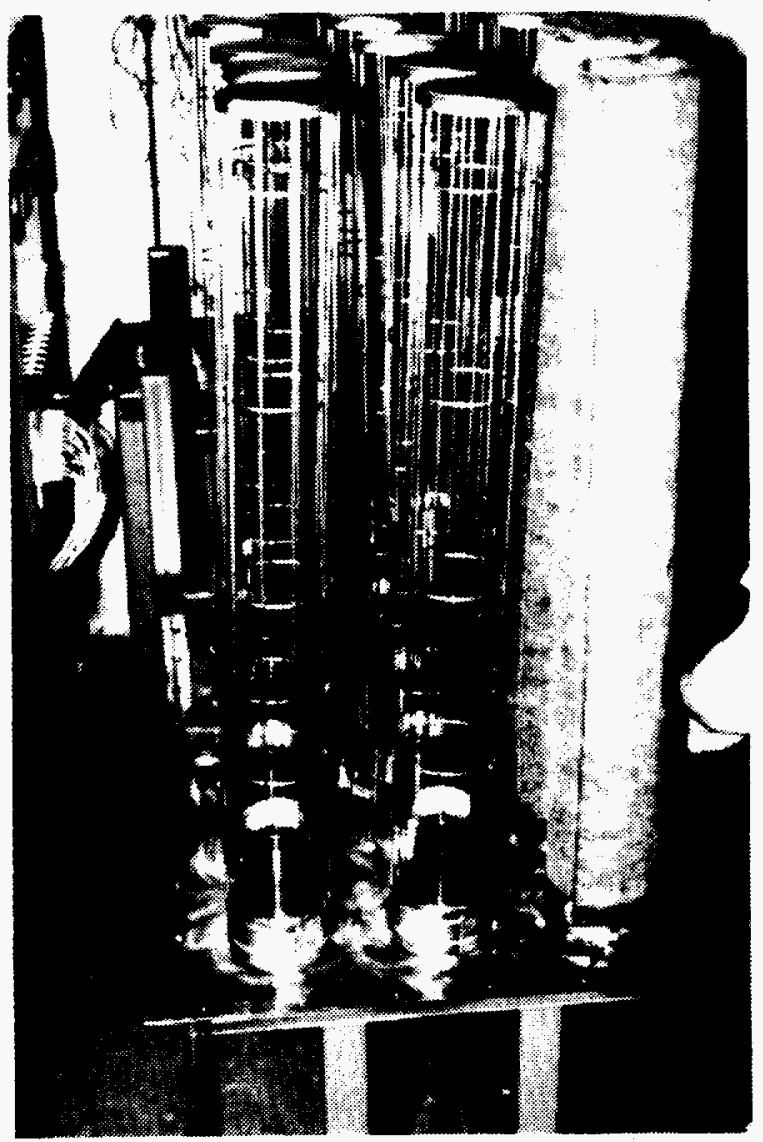

Figure 3.29 Venturis and Cages 
The baghouse was designed to have two separate chambers within the single baghouse. In this way, the same unit could be used for both the $\mathrm{NO}_{\mathrm{x}}$ and $\mathrm{SO}_{2}$ test facilities.

\subsection{TASK 7.1 - PRELIMINARY MANUFACTURING COST ESTIMATE}

When the high-volume manufacturing cost of the emissions control system hardware was estimated, the system was broken up into three major subassemblies. These were the sorbent feeder and storage hopper, the $\mathrm{SO}_{2}$ reactor, and the particulate collector, or baghouse. The cost estimate was performed at two levels of detail. The first and most conservative was to simply cost out the components as discrete items patterned after the laboratory unit, but built in high volume. However, since such a design would go through a detalled value engineering analysis belore going into production, a second level of cost refinement was done. In this second instance, it was assumed that except for purchased component assemblles (motors, controls, fittings) the major components would be fabricated and assembled in a high-volume production facility. As such, steel plate would arrive as rolled stock, ready to be cut and formed with in-house presses. Also, all purchased components would be purchased directly from the manufacturer and not through local distributors.

In the preliminary cost analysis, the manufacturing cost of the screw feeder assembly, $\mathrm{SO}_{2}$ reactor assembly, and baghouse were $\$ 322, \$ 336$, and $\$ 378$. respectively. Since the original manufacturers would have already taken a substantlal markup (often over 100 percent), it was anticipated that these costs should come down by a factor of two or more.

In the second level of cost refinement, shown in Table 3.5, significant cost reductions were indeed projected. The screw feeder assembly was reduced by 27 percent to $\$ 236$. However, the major component cost remains the auger screw and gear motor drive. As such, alternative feed systems such as pneumatic or vibratory may prove to be more cost-effective at this scale.

The $\mathrm{SO}_{2}$ reactor assembly was reduced by almost 66 percent. Since almost all the components were assumed to be fabricated from sheet stock, this cost reduction was made possible. The baghouse assembly was reduced by almost 44 percent to $\$ 213$. Again, this was achieved by in-house fabrication of sheet metal components.

While these costs should still be considered preliminary until detailed component designs have been completed, there remains an additional and potentially significant level of cost reduction. In the previous analyses, the 
TABLE 3.5

MANUFACTURING COST ESTIMATE

\begin{tabular}{|c|c|c|c|c|c|c|c|c|}
\hline $\mathrm{SO}_{2}$ Emissions Control System & Quantity & $\begin{array}{l}\text { Unit } \\
\text { Cost }\end{array}$ & Steel & $\begin{array}{l}\text { Purchased } \\
\text { Parts }\end{array}$ & $\begin{array}{l}\text { Material } \\
\text { Handling }\end{array}$ & Labor & Overhead & Total \\
\hline $\begin{array}{l}\text { I. SCREW FEEDER ASSEMBLY } \\
\text { Auger Screw } \\
\text { A.C. Gearmotor } \\
\text { Motor Controls } \\
\text { Storage Tank, C.S. } 18 \text { ga } \\
\text { Structural Support, CS } \\
\text { Miscellaneous Fittings } \\
\text { Components Assembly } \\
\text { SUBTOTAL } \\
\end{array}$ & $\begin{array}{c}1 \\
1 \\
1 \\
31 \mathrm{lb} \\
30 \mathrm{lb} \\
\square\end{array}$ & $\begin{array}{l}\$ 60 \\
\$ 55 \\
\$ 30 \\
\$ 0.35 / \mathrm{lb} \\
\$ 0.35 / \mathrm{lb}\end{array}$ & $\begin{array}{l}10.85 \\
10.50\end{array}$ & $\begin{array}{l}60.00 \\
55.00 \\
30.00 \\
15.00\end{array}$ & $\begin{array}{l}6.00 \\
5.50 \\
3.00 \\
\\
1.50\end{array}$ & $\begin{array}{l}2.00 \\
2.00 \\
9.00\end{array}$ & $\begin{array}{r}4.00 \\
4.00 \\
18.00\end{array}$ & $\begin{array}{r}\$ 66.00 \\
60.50 \\
33.00 \\
16.85 \\
16.50 \\
16.50 \\
27.00 \\
\$ 236.35\end{array}$ \\
\hline $\begin{array}{l}\text { II. } \mathrm{SO}_{2} \text { REACTOR ASSEMBLY } \\
\text { Main Body, S.S., } 16 \text { ga } \\
\text { Internal Partition, S.S., } 16 \text { ga } \\
\text { Top and Bottom Headers, S.S., } 16 \text { ga } \\
\text { Recirculation Line, S.S., } 16 \text { ga } \\
\text { Inlet Duct, S.S., } 16 \text { ga } \\
\text { Exhaust Duct, S.S., } 16 \text { ga } \\
\text { Insulation } \\
\text { Miscellaneous Fittings } \\
\text { Components Assembly } \\
\text { SUBTOTAL }\end{array}$ & $\begin{array}{r}19 \mathrm{lb} \\
1 \mathrm{lb} \\
2 \mathrm{lb} \\
5 \mathrm{lb} \\
2 \mathrm{lb} \\
2 \mathrm{lb} \\
20 \mathrm{ft}^{2} \\
-\end{array}$ & $\begin{array}{l}\$ 1.60 / \mathrm{lb} \\
\$ 1.60 / \mathrm{lb} \\
\$ 1.60 / \mathrm{lb} \\
\$ 1.60 / \mathrm{lb} \\
\$ 1.60 / \mathrm{lb} \\
\$ 1.60 / \mathrm{lb} \\
\$ 0.90 / \mathrm{ft}^{2}\end{array}$ & $\begin{array}{r}30.40 \\
1.60 \\
3.20 \\
8.00 \\
3.20 \\
3.20 \\
18.00\end{array}$ & 15.00 & 1.50 & $\begin{array}{l}2.00 \\
0.20 \\
0.40 \\
1.00 \\
0.20 \\
0.20 \\
1.00 \\
6.00\end{array}$ & $\begin{array}{l}4.00 \\
0.40 \\
0.80 \\
2.00 \\
0.40 \\
0.40 \\
2.00 \\
12.00\end{array}$ & $\begin{array}{r}\$ 36.40 \\
2.20 \\
4.40 \\
11.00 \\
3.80 \\
3.80 \\
21.00 \\
16.50 \\
16.00 \\
\\
\$ 115.10\end{array}$ \\
\hline
\end{tabular}


TABLE 3.5 (Continued)

MANUFACTURING COST ESTIMATE

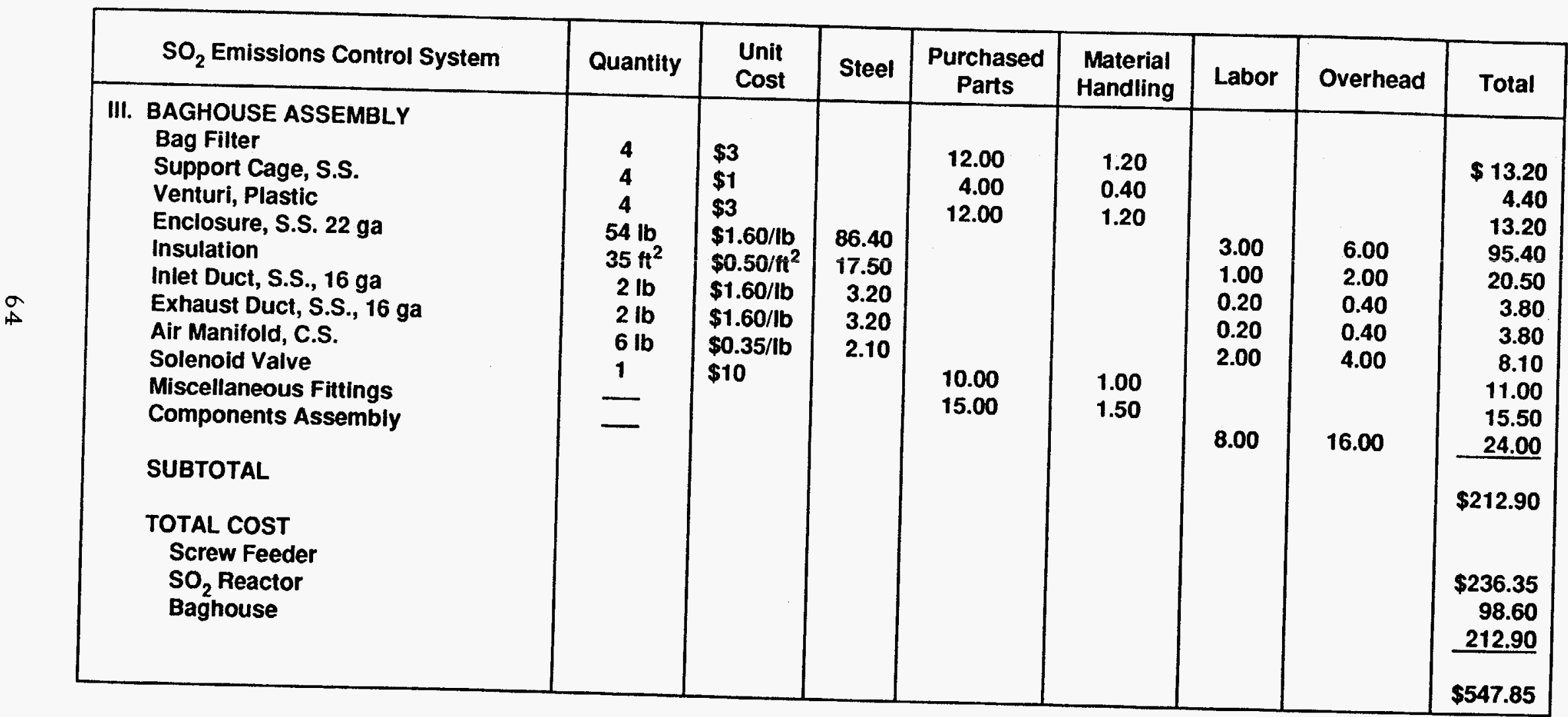


components were costed as discrete assemblies. However, in a real system, these assemblies would be engineered to function as an integrated unit, with components serving in dual roles. For example, the baghouse enclosure can also possibly serve as a heat transfer surface between the combustion gas and circulation airstreams. In this way, the original gas-to-air heat exchanger will be much smaller or not necessary at all. Thus, the total system should be more cost-effective. This final cost analysis will be done once the final design has been established and detalled drawings made. 


\section{SUMMMARY STATUS ASSESSMENT AND FORECAST}

During the first year of this program, several major project milestones were met. These include the construction of two test facilities for $\mathrm{NO}_{\mathrm{x}}$ and $\mathrm{SO}_{2}$ reduction testing, the development of a model to predict the performance of the $\mathrm{SO}_{2}$ reduction reactor operating under various conditions, as well as obtaining $\mathrm{NO}_{\mathrm{x}}$ and $\mathrm{SO}_{2}$ reduction data. In addition, preliminary manufacturing cost estimates were obtained so that a system economic analysis can be performed. Test results from the $\mathrm{NO}_{x}$ and $\mathrm{SO}_{2}$ test facilities have shown that:

- $\mathrm{NO}_{\mathrm{x}}$ levels of $0.285 \mathrm{lbm} / \mathrm{MMBtu}$ under staged combustion conditions have been achieved. This represents a 65-percent reduction compared to uncontrolled emissions levels.

- Reduction levels in $\mathrm{SO}_{2}$ have exceeded model predictions.

During the next year of the program, work will continue on lowering $\mathrm{NO}_{\mathrm{x}}$ levels to the $0.2 \mathrm{lbm} / \mathrm{MMBtu}$ level that is required. This will include altering the combustor geometry further and lowering the temperature in the combustor primary zone. For the $\mathrm{SO}_{2}$ reactor, extensive testing will be conducted in order to obtain data on the effect of $\mathrm{SO}_{2}$ concentration, flow rate, particle size distribution. and reactor diameter in an effort to determine the optimum operating conditions for a residential-scale reactor. Upon obtaining the required $\mathrm{NO}_{\mathrm{x}}$ and $\mathrm{SO}_{2}$ levels, the components will be integrated together to form a fully operational CWS furnace system that will be tested extensively. At the point where the baghouse must handle both fly ash and spent sorbent simultaneously, detalled particulate capture testing will be performed. 


\section{REFERENCES}

1. Elliot, M.A., ed., "Chemistry of Coal Utilization - Second Supplementary Volume," John Wiley, NY, 1981.

2. Smoot, L.D. and Smith, P.J., "Combustion and Gasification of Coal, Char and Coal/Water Mixtures," Course Notes, 1982.

3. Field, M.A., Gill, D.W., Morgan, B.B., and Hawksley, P.G.W., "Combustion of Pulverized Coal," British Coal Utilization Research Association, Cheney and Sons, Leatherhead, 1967.

4. Smoot, L.D. and Pratt, D.T., ed., "Pulverized-Coal Combustion and Gasification," Plenum Press, NY, 1979.

5. Levenspiel, O., "Chemical Reaction Engineering," John Wiley \& Sons, NY, 1972.

6. Dooher. J.P. et al., "Handling Properties of Coal Water Slurry Fuels," Seventh International Symposium on Coal Slurry Fuel Preparation and Utilization, New Orleans, LA, May 1985.

7. Miller, B.G., "Coal-Water Slurry Fuel Utilization in Utllity and Industrial Bollers," CEP, p. 29, March 1988.

8. Szymanski, J.K. and Mansour, N.A., "Time Dependent Rheology of a Western Canadian Coal Water Fuel," Eighth International Symposium on Coal Slurry Fuel Preparation and Utilization, Orlando, FL, May 1986.

9. Chan, L.K., Sarofin, A.F., and Beer, J.M., "Kinetics of the NO Carbon Reactive at Fluidized Bed Combustor Conditions," Combustion and Flame, 52, 1983.

10. Sarofin, A.F., "Fluidized Bed Coal Combustion: Controlling Parameters," Chemical Reaction Engineering, ACS, 1983.

11. Hirama, T., Tekeuchi, T., and Horio, M., "Nitric Oxide Emissions from Circulating Fluidized-Bed Coal Combustion," Ninth International Fluidized Bed Combustion Conference, Boston, MA, 1987.

12. Breault, R.W., "NO ${ }_{x}$ Emissions from a Staged Circulating Fluidized Bed Process: The MSMBC," ASME Winter Annual Meeting, Boston, MA, 87-W/FACT-2, December 1987.

13. Borgwardt, R.H., "Kinetics of the Reaction of $\mathrm{SO}_{2}$ with Calcined Limestone," Environmental Science and Technology. Vol. 4, No. 2, 59, 1970.

14. Lee, D.C., Georgakis, C., and Hodges, J.L., "Modeling $\mathrm{SO}_{2}$ Emissions from Fluidized Bed Coal Combustors," Chem. Eng. Sci., Vol. 35, 302, 1980.

15. Lee, D.C. and Georgakis, C., "A Single, Particle Size Model for Sulfur Retention in Fluidized Bed Coal Combustors," AIChE Journal, Vol. 27, No. 3, 476, 1981. 
16. Wen, C.Y. and Ishida, M., "Reaction Rate of Sulfur Dioxide with Particles Containing Calcium Oxide." Environmental Science and Technology, Vol. 7, No. $8,703,1973$.

17. Hartman, M. and Coughlin, R.W., "Reaction of Sulfur Dioxide with Limestone and the Grain Model," AIChE Journal, Vol. 22, No. 3, 490, 1976.

18. Breault, R.W., "Sulfur Removal Modeling in a Circulating Fluidized Bed: The Multisolids Fluidized Bed Combustor," 1987 AIChE Presented at the National Meeting Houston, TX. March 1987.

19. Breault, R.W., "Theoretical Modeling of the Multisolids Fluidized Bed Combustor: Hydrodynamics, Combustion, and Desulfurization," Proceedings of the Ninth International Conference on Fluidized Bed Combustion, Boston. MA, May 1987.

20. Zenz, F.A., "State of the Art Review and Report on Critical Aspects and Scale Up Considerations in the Design of Fluid Bed Reactors," Phase I Final Report, $\mathrm{DOE} / \mathrm{MC} / 14141-1158$. 